Portland State University

PDXScholar

2-10-1984

\title{
Developmental Sentence Scoring: A Comparative Study Conducted in Portland, Oregon
}

Kathryn Marie McCluskey

Portland State University

Follow this and additional works at: https://pdxscholar.library.pdx.edu/open_access_etds

Part of the Developmental Psychology Commons, and the Speech Pathology and Audiology Commons

Let us know how access to this document benefits you.

\section{Recommended Citation}

McCluskey, Kathryn Marie, "Developmental Sentence Scoring: A Comparative Study Conducted in Portland, Oregon" (1984). Dissertations and Theses. Paper 3383.

https://doi.org/10.15760/etd.5250

This Thesis is brought to you for free and open access. It has been accepted for inclusion in Dissertations and Theses by an authorized administrator of PDXScholar. Please contact us if we can make this document more accessible: pdxscholar@pdx.edu. 
AN ABSTRACT OF THE THESIS OF Kathryn Marie McCluskey for the Master of Science in Speech Communication, with an emphasis in Speech-Language Pathology, presented February 10, 1984.

Title: Developmental Sentence Scoring: A Comparative Study Conducted in Portland, Oregon.

APPROVED BY MEMBERS OF THE THESIS COMMITTEE:

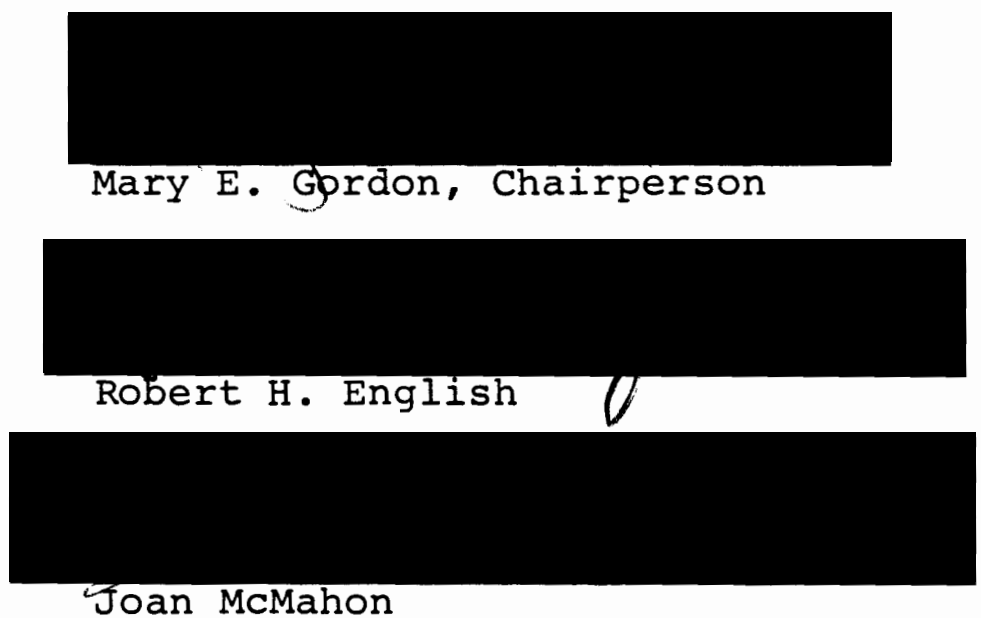

Oral language sampling and analysis are tools available to the speech-language clinician, which are often helpful in obtaining information regarding the development of expressive language in children. In the past, a child's language has been judged to be mature based upon the length of the utterance and/or the grammatical complexity. 
The purpose of this investigation was to replicate the study conducted by Lee and Canter (1971) and Lee (1974a) to determine if a significant difference among the scores in the two studies existed due to geographical location, and to initiate the establishment of norms for the Portland, oregon geographical area. Forty children, selected on the basis of chronological age ( 4.0 to 4.11 years), normal receptive vocabulary skills, normal hearing, and a monolingual background, participated as subjects. A language sample of fifty utterances was elicited from each child and analyzed according to the Developmental Sentence Scoring (DSS) procedure. DSS means, standard deviations, percentiles, range of the average score, mean weighted developmental score for each grammatical category, and mean number of DSS utterances earning a sentence point were compiled. A t-test analysis was conducted to determine if a difference exists between the means of the scores for the two geographical locations.

A significant difference resulted between the mean scores obtained in the Midwest and in Portland, Oregon. The results indicate that a statistically significant difference in the mean DSS score exists $(p<.05)$ and may be attributable to differences in the geographical location in which the scores were obtained. Differences in scores do not appear to be attributable to variables in subject selection, i.e., socio-economic background, receptive language vocabulary scores, etc.

Although slight variation in the examiner's form 
of elicitation and use of stimulus materials may possibly explain some of the differences found in the grammatical categories, it appears an unlikely possibility that this variation could account for the statistically significant difference found between the mean DSS scores of the two studies. In addition, the differences do not appear to be the result of stimulus materials or transcription methods used.

The norms compiled by Lee (1974a) in the Midwest, differ significantly from those obtained in this study, conducted in Portland, oregon. It appears likely that score differences in other geographical areas may exist as well. In order to conduct a thorough and competent evaluation of a child's expressive language abilities, the data from this investigation reflect the need for the speech-language clinician to use the DSS norms cautiously and/or to establish norms specific to a geographical region. 
DEVELOPMENTAL SENTENCE SCORING: A COMPARATIVE STUDY CONDUCTED IN PORTLAND, OREGON

by

KATHRYN MARIE MCCLUSKEY

A thesis submitted in partial fulfillment of the requirements for the degree of

MASTER OF SCIENCE IN SPEECH COMMUNICATION:

with an emphasis in

SPEECH-LANGUAGE PATHOLOGY/AUDIOLOGY

Portland State University 
TO THE OFFICE OF GRADUATE STUDIES AND RESEARCH:

The members of the Committee approve the thesis of Kathryn Marie McCluskey presented February 10, 1984.

Mary E. Ggrdon, Chairperson

Robert H. English

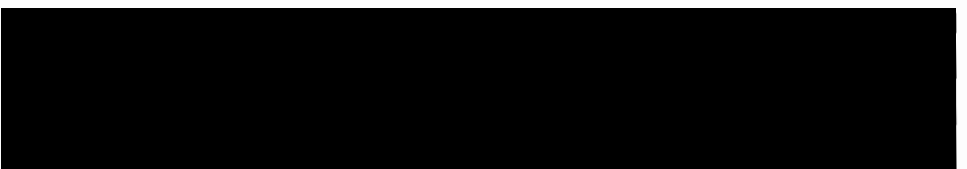

Jöan McMahon

APPROVED :

Theodore G. Grove, Chair, Department of Speech Communication

Stanley E. Rauch, Dean, Graduate Studies and Research 


\section{DEDICATION}

This thesis is dedicated to Richard, my husband and "best friend," who, by giving me his love and support, made this study a joy that was shared. This thesis is also dedicated to my sons, Christopher and Andrew, who, by their development of verbal expression, have made the phenomenon of language a wonder to behold. 


\section{ACKNOWLEDGMENTS}

The process of researching, conducting, writing, and typing a thesis is much like giving birth to a child. When one holds the final product of such an endeavor, one can't help thinking of it as a miracle. I am proud of my "baby" because it represents my own efforts and those of many others who helped guide me.

I am most grateful to my thesis director and friend, Mary Gordon, for her suggestions and encouragement. She gave freely of her time and professional experience. Thank you, Mary, for making this project such a joy. I also wish to thank Dr. Robert English for both acting as my advisor and consultant. To Joan McMahon, who never hesitated to request the best from me. Joan, I will miss you! A special thanks to Dr. Theodore Grove for his tremendous guidance in interpolating statistical data.

I appreciate the staff, parents, and children at Helen Gordon Child Development Center, Pencil Pals Preschool, Fruit and Flower Preschool, and Kinderland for their invaluable participation.

Finally, I wish to thank my family for giving me the greatest gift: an insatiable thirst for enriching my life through education. Thank you for the years of love, faith, and gentle guidance. It is my hope that I might contribute in like manner to Christopher and Andrew's futures. 
TABLE OF CONTENTS

Page

DEDICATION

ACKNOWLEDGMENTS

iv

LIST OF TABLES

CHAPTER

I INTRODUCTION AND STATEMENT OF PURPOSE 1

Introduction . . . . . . . . . . . . 1

Statement of Purpose . . . . . . . . . 3

II REVIEW OF THE LITERATURE 4

Types of Oral Language Sampling . . . . 4

Response Length . . . . . . . . . 5

Grammatical Complexity . . . . . . . . 5

Factors Influencing Elicitation and

Transcription of Oral Language

Sampling . . . . . . . . . . . . 7

Using Normative Data in the Analysis of

Oral Language Sampling .. . . . . 10

Developmental Sentence Scoring . . . . 11

The Use of Developmental Sentence

Scoring .............. 13

The Need for Geographical Comparison

of the DSS ............ 15

$\begin{array}{ll}\text { III METHODS AND PROCEDURES } & 17\end{array}$

Subjects . . . . . . . . . . . 17

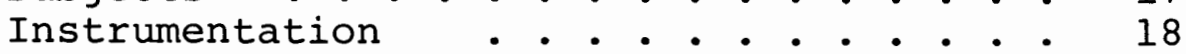

Screening .. . . . . . . . . . . 19

Language Sample Collection . . . . . 19

Language Sample Transcription . . . . 21

Scoring . . . . . . . . . . . 21

Examiner Relibability .. . . . . . 22

Data Analysis . . . . . . . . . 23

IV RESULTS AND DISCUSSION

Results •. . . . . . . . . . . 24 


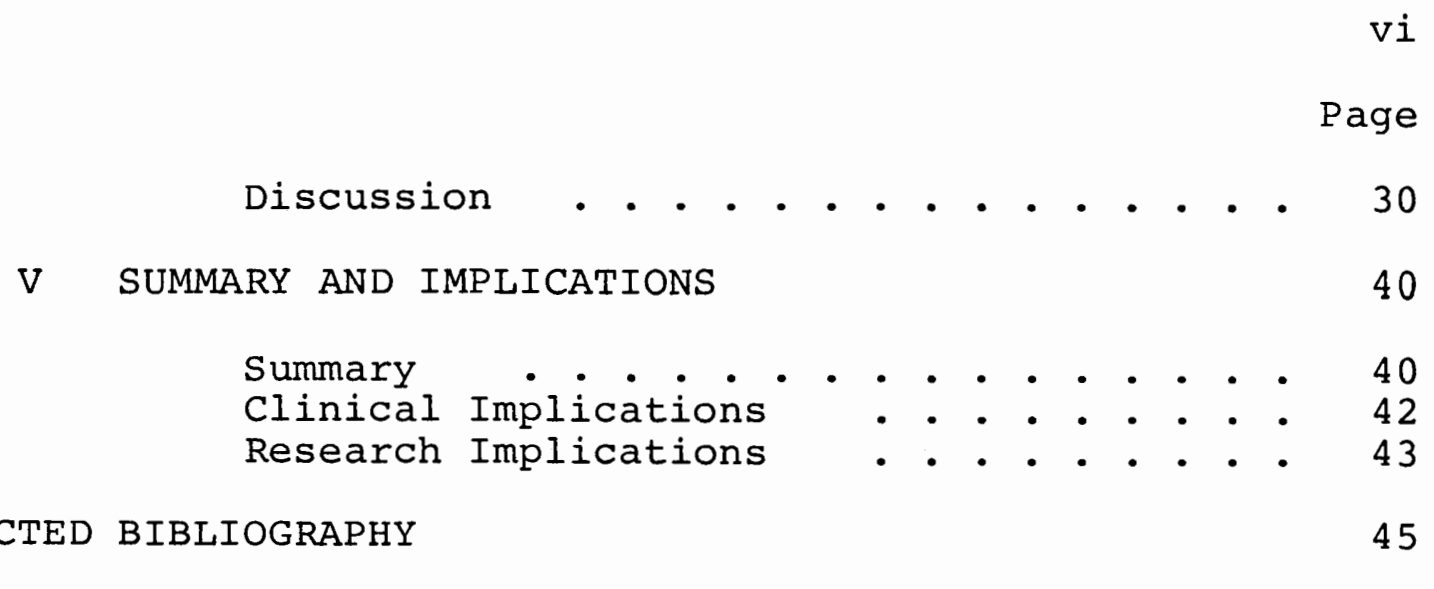

APPENDICES • • • • • • • • • • • • • • • • • • • • 50 


\section{LIST OF TABLES}

TABLE

Page

I DSS Means and Standard Deviations of Forty Subjects by Three-month Age Groups (Portland, Oregon) . . . . . . . . . . 26

II Range and Percentiles of DSS Scores for Forty subjects by Three-month Age Groups

II Mean Weighted Developmental score on the DSS Component Grammatical Categories and Mean Number of Sentence Points for Forty Subjects . . . . . . . . . . .

IV Mean Developmental Scores per DSS Grammatical Category on 50-Utterance Samples for Forty Subjects . . . . . . . . . . . . . .

V Comparison of DSS Means and Standard Deviations obtained in the Midwest and Portland, oregon

VI Comparison of Mean Weighted Developmental Scores on the DSS Component Grammatical Categories and Mean Number of Sentence Points for Forty Subjects by Geographical Location

VII Comparison of Mean Developmental Scores per DSS Grammatical Category by Geographical

VIII Comparison of Range and Percentiles of DSS Scores for the Midwest and Portland, Oregon for Children 4.0 through 4.11 Years

IX Comparison of Number of Subjects per Percentile Rank Using Midwest Norms and Portland, Oregon Norms 
CHAPTER I

INTRODUCTION AND STATEMENT OF PURPOSE

\section{Introduction}

In the past three decades, research in the field of speech and communication sciences has focused on the development of normal language acquisition. Semantic and syntactic components of language are the emphasis for investigators seeking more information regarding language; no longer do the phonological aspects of language serve to describe language development in children.

Elaborate psycholinguistic studies on language deve1opment of a few children have provided valuable information on the growth of syntactic structures, utilizing Chomsky's (1957, 1965) transformational grammar as the basis of analysis (Brown and Fraser, 1964; McNeill, 1966; Bloom, 1970). Additionally, based on recorded language samples, many investigators have informally traced the development of a single grammatical category with children of successive chronological ages (Menyuk, 1964; Klima and Bellugi, 1966; Brown, 1968; Bloom, 1970).

While the methods for syntactic structure analysis in these investigations have varied, the assumption is that words which occupy the same position in a series form a 
grammatical class and are developmental in nature. Therefore grammatical rules could be written to account for this development (McNeill, 1970). A systematic method was needed to compare these sets of rules and to determine syntactic growth.

In 1971, Lee and Canter provided a systematic tool for assessing children's expressive language: Developmental Sentence Scoring (DSS). A specific scoring system was developed and normative data were collected in order to estimate the grammatical complexity of children's speech. By analyzing a child's spontaneous, tape-recorded speech sample, the speech-language clinician is able to estimate the extent to which grammatical rules have been sufficiently generalized for use in the child's verbal performance. In recent years, the DSS has been used as a comparative measure in speech and language studies and used extensively as an analytical tool in determining expressive language delay (Carrow, 1974b; Longhurst and File, 1977; Kramer, James, and Saxman, 1979).

There appear to be no studies reported in the literature investigating the extent to which descriptive DSS normative data varies dependent upon the geographical area in which it was obtained. The need exists to provide comparative data from a variety of geographical areas in order to support or refute rationale for interpretation of language performance based upon data obtained in the Midwest (Koenigsknecht, 1974). 


\section{Statement of Purpose}

The purpose of this study was to compare DSS normative data (Koenigsknecht, 1974), with the data obtained in Portland, Oregon, for children ages 4.0 to 4.11 years. A secondary purpose was to initiate the development of norms for the geographical area of Portland using the DSS procedure.

The essential questions this investigation sought to answer were:

1. What are the descriptive statistics of the DSS on language samples obtained in Portland, Oregon, $r \in$ presented by:

a. the DSS mean and standard deviation of the overall DSS score;

b. the range and percentiles of the average DSS sentence score;

c. the mean weighted developmental scores for each of the DSS component grammatical categories; and

d. the mean number of DSS utterances earning a sentence point for grammatical completeness?

2. Is there a significant difference in the mean DSS score obtained by Lee (1974a) and reported by Koenigsknecht (1974) in the Midwest and that obtained in Portland, Oregon? 


\section{REVIEW OF THE LITERATUPE}

Oral language sampling, as a research and clinical technique, is a valuable tool for assessing the level of expressive language development in young children. This review of the literature presents historical information regarding the types of expressive language analyses and the variables that may influence the elicitation and transcription of these systems. Since the DSS is the focus of this research, a description of the procedures, population, and geographical area used in standardizing the DSS system is presented in.order to provide information on the normative data of the original studies (Lee and Canter, 1971; Lee, 1974a). Clinical use and interpretation of these normative data are described. Finally, studies indicating the need for conducting investigations in various geographical areas in oral language sampling are presented.

\section{Types of Oral Language Sampling}

The past fifty years have witnessed a variety of language sampling analysis systems. The earliest procedures focused on the length of a child's utterance rather than on grammatical complexity. 


\section{Response Length}

Mean Length of Response

Nice (1925) postulated that the average length of a child's sentence be used as an index of a child's language development. In 1930, McCarthy measured children's language using fifty consecutive, verbatim, verbal utterances as elicited through the use of pictures, books, and toys; the number of words per response was averaged, yielding a Mean Length of Response (MLR).

Mean Length of Utterance

Mean Length of Utterance (MLU) represents the average sentence length as measured in morphemes, rather than words, and has been used by many recent investigators (Brown, 1973; Tyack, 1974).

\section{Other Measures of Length}

Minifie, Darley, and Sherman (1963) analyzed children's expressive language based on the Mean of the Five Longest Responses; the Total Number of Words has been employed by Hass and Wepman (1973).

\section{Grammatical Complexity}

Investigators discovered the length of a child's utterance did not provide sufficient information regarding the expressive maturity or complexity of a child's language. Measures were thus created to describe a child's language in 
terms of structural complexity.

Structural Complexity Scale

The Structural Complexity Scale (SCS) was developed by McCarthy $(1930)$ to measure grammatical complexity and completeness. Utterances were divided into complete and incomplete responses and classified as to sentence type.

Length of Complexity Index

Miner (1969) used the Length of Complexity Index (LCI) as an analysis of sentence complexity and length according to a numeric weighting system in which the final score is the sum of the points assigned for noun-phrases, verb-phrases, and additional points for questions and negatives, divided by the number of sentences.

Developmental Sentence Scoring

Lee and Canter (1971) and Lee (1974a) used the Developmental Sentence Scoring (DSS). This measure was designed to specify the developmental level of a child's grammar by weighted scoring of selected syntactical structures in complete sentences. Based on a corpus of fifty complete, different, consecutive, non-echoic sentences, weighted scores are assigned to the following eight grammatical classifications: indefinite pronouns and/or noun modifiers, personal pronouns, main verbs, secondary verbs, negatives, conjunctions, interrogative reversals, and wh-questions. An additional point is given if the entire sentence is grammatically 
and semantically correct according to adult Standard English.

Factors Influencing Elicitation and Transcription of Oral Language Sampling

With the development of a variety of analytical systems for evaluating children's expressive language, the need now exists to control the effects of variables, whenever possible, on clinical oral language sampling. Speech-language clinicians must be aware of the variables affecting elicitation and transcription of oral language in order to manipulate them systematically to derive representative and meaningful results.

There are many factors which influence the "representativeness" of a child's oral language from elicited samples. Studies involving subject variables, such as socio-economic status and sex reflect differences in language performance. For example, lower socio-economic groups use shorter language utterances, fewer morphemes, and less complex grammatical structures (McCarthy, 1930; Jones and McMillan, 1973). Watson (1976) found four-year old males produced more mature language as measured by MLU as compared to females' elicitations.

The literature suggests that the interaction of subject anà examiner characteristics can affect the syntactical sophistication of the child's utterance. For example, in most studies reviewed, the examiner was an adult (McCarthy, 1930; Templin, 1957). In several recent stuaies, however, other 
children interacted with the subject (Jones and McMillan, 1973; Welkowitz, Cariffe, and Feldstein, 1976). Differences in verbal length and complexity due to the interaction with other chilaren were not reported by these investigators. Shatz and Gelman (1973) studied the ability of fouryear olds to adjust to a listener and found that all subjects adjusted their oral language on the basis of the listener's age. Language addressed to two year olds was characterized by shorter, less complex utterances than that addressed to adults.

Comparison of samples collected in a variety of settings, e.g., home, clinic, and playroom, have been made (Mueller, 1972; Johnson, 1974; Longhurst and Grubb, 1974). Unfortunately, none of these studies compared samples in which all the variables except the setting variable were held constant. Therefore, it is not possible to determine, from these investigations, the influence of different settings on the quantity and quality of a child's expressive language.

Persons or objects located in the room may have an effect on the language sample obtained. Smith (1970) found a significantly greater amount of speech in terms of total number of words and responses when three other chilaren were present, than when the child was alone with the examiner.

The type of stimulus material may affect the quality as well as the quantity of expressive language. Mintun (1968) presented toys, still pictures, and movies to three groups of educable mentally retarded children and found the film medium 
elicited significantly higher LCI scores than pictures. The toy medium resulted in a larger number of different words and a higher MLR score. Ahmed (1973) presented both single object and multi-object pictures to elicit language samples. The study found multi-object pictures yielded higher scores for LCI and MLR.

Few, if any, studies have reported the effects of instructions and/or modeling procedures on oral language, although several investigators have noted the need for such research (Cowan, Weber, Hoddinott, and Klein, 1967; Jones and McMillan, 1973; Longhurst and Grubb, 1974).

It appears, from the literature, that variations in written transcription affect oral language sampling results. Siegel (1962) suggested that the use of longhand recording of MLR increased the inaccuracy of obtaining values. Betts (1934) described a study in which oral language recordings represented only 32 percent of the children's utterances when recorded in longhand. Contextual factors, intelligibility, complexity, and/or response length, and the transcriber's training may influence live and taped transcriptions (BarrieBlackley, Musselwhite, and Rogister, 1978).

Siegel (1962) also emphasized the importance of designating remarks and questions made by the examiner, especially with regard to sampling language of very young children in non-clinical settings. Noting utterances made by the examiner has provided a context, enabling the clinician to transcribe samples more accurately. 
In preparing transcriptions, the segmentation of a child's verbalizations into units is an important issue and many investigators have found it necessary to use specific transcription and segmentation rules. For example, McCarthy (1930) considered a response to be a separate unit "if it was marked off from the preceding and succeeding remarks by pauses." Siegel (1962) defined a vocal unit as being "marked off on either side by a pause or by some change in inflection." With regard to segmenting a sample, Lee (1974a) states, "The transcriber must use intonational cues." Additionally, she provided other segmentation strategies in the form of five rules for segmenting compound sentences (Appen$\operatorname{dix}$ A) .

Failure to control variables and/or report specific methodology has made comparison studies and standardization nearly impossible.

Using Normative Data in the Analysis of Oral Language sampling

Leonard (1972) noted that the lack of uniform and carefully controlled procedures in oral language sampling might invalidate conclusions or result in misinterpretations and inappropriate management procedures and cautioned clinicians about the use of normative data.

In order to use normative data provided by researchers in the area of expressive language, it is necessary to be cognizant of the nature of the sample, the geographical area 
in which it was obtained, and the procedures in which an analysis system has been standardized. Knowledge of specific normative information must exist prior to clinical evaluation. The DSS is the focus of this investigation, and, therefore, a description of the population, procedures, and geographical area is provided below.

\section{Developmental Sentence Scoring}

The DSS procedure was originally conducted by Lee and Canter (1971) on 160 children who were 3.0 to 6.11 years of age and who were not enrolled in the Northwestern Speech Clinic at Northwestern University, Chicago, Illinois. The subjects were selected to represent a "midline" of as many variables as could be controlled. All the children were from nonolingual homes where standard English was spoken and all were judged to be from middle-income families, with the exception of two, according to the Warner scale (Warner, Meeker, and Eells, 1949). All the children obtained IQ scores between 85 and 115 on the Peabody Picture Vocabulary Test (PPVT) (Dunn, 1965). Five males and 5 females were selected from each three-month age group, assuring equal representation by sex and equal distribution of ages within six-month age groups.

In a later study conducted in 1974,40 additional subjects between the ages of 2.0 and 2.11 years were selected to increase the sample size to 200. The sample of 200 included 
"normally developing white children between the ages of two years to six years and eleven months" who resided in Illinois, Michigan, and Maryland (Lee, 1974a). All criteria from the previous study were met, with the exception of 3 subjects, 2 who were judged to be slightly below the middle income group and 1 subject who was not "classifiable" according to the Warner scale. These subjects were included in the study, however. No children with unusual developmental or social histories, suspected hearing sensitivity problems, or poor speech intelligibility were included.

Both studies attempted to keep the recording sessions as systematic as possible in a conversational setting. Interviewers were "speech and language pathologists at the master's degree level." The subjects were first shown three sets of toys: a small barn and farm animals, a doll family and plastic funiture, and a transport truck; they were encouraged to talk about them. Story action pictures from We Read Pictures, We Read More Pictures and Before We Read (Robinson, Monroe, and Artley, 1962 a, b, c) were presented. Children were encouraged to retell the story "The Three Bears" using the pictures from What's Its Name? (Utley, 1950). The recording sessions varied in length from 15 to 30 minutes, depending upon the "talkativeness" of the subject. All sessions were tape recorded. Clinicians used questions which encouraged subjects to use their most highly developed syntactic structures and morphological forms. The last fifty sentences of the session were selected for scoring and analysis. 
Clinicians transcribed the corpus, making allowances for articulation errors, grammatical reformations, non-fluencies, and word finding difficulties.

Descriptive data were collected. The score distributions within each age group were fitted to normal curves and percentile values were computed from the normalized distributions for the $90 \mathrm{th}, 75 \mathrm{th}, 50 \mathrm{th}, 25 \mathrm{th}$, and $10 \mathrm{th}$ percentiles.

\section{The Use of Developmental Sentence Scoring}

There are countless studies appearing in the literature which have reported using DSS as a means of determining a language delay of a given subject or group, as well as establishing criteria for "normal" language development. These studies have been conducted in a variety of geographical areas. In interpreting the results, investigators have assumed that the DSS norms can be generalized to their given geographical area and/or population.

Carrow (1974a), in Houston, Texas, used the DSS normative data as a reference for establishing "normal" language development guidelines, i.e., DSS scores above the loth percentile, in creating an elicited imitation measurement of expressive language. This measure is a widely used test, designed to assess linguistic structures through repetition of sentences rather than eliciting spontaneous language samples. Carrow reported the DSS and the Carrow Elicited Language Inventory (CELI) (Carrow, 1974b) successfully separated those subjects considered to have normal language and those 
considered to be language disordered. The correlation between the DSS and the CELI was .79 ( $p<0.005)$, indicating a strong relationship between the two methods of obtaining grammatical data. It appears, from the research, that Carrow has reported good construct validity due to statistically significant agreement between CELI scores and DSS scores. Other investigators have used the DSS to compare different procedures within a particular study. Longhurst and File (1977) in Manhattan, Kansas, computed DSS scores on language samples under four conditions: single-object picture, toy, multi-object picture, and adult-child conversation. Analysis of the data revealed that less structured elicitation conditions produce the highest DSS score. In St. Louis, Missouri, Geers and Moog (1978) used the DSS and the CELI to compare the syntactic maturity of the spontaneous speech of normal hearing and hearing impaired children. In syracuse, New York, Kramer, James, and Saxman (1979) compared language samples obtained in the home by mothers with those obtained in the clinic by speech-language clinicians, using the DSS. The investigators found that, although MLU was greater in the home setting, there were no quantitative differences in DSS scores. Seven of the 10 subjects, however, had higher estimated language ages on the DSS for the home sample. In Portland, Oregon, Valenciano (1981) used the DSS to compare scores obtained from 25, 50, and 75 utterance language samples and found that no significant differences resulted among scores for different size samples. 
The Need for Geographical Comparison of the DSS

Although the DSS is widely used as an assessment tool of language development in children, a review of the literature reveals little investigation concerning the validity of the DSS in various geographical areas. Many authors, however, have questioned the validity of the use of other language measures in geographical areas in which the norms were originally obtained. Lyman (1965) stated in his summary of the PPVT, "...considerable caution needs to be used in interpreting the norms, especially in communities other than Nashville." Butler (1972) stated in her summary of the Verbal Language Development Scale, that the normative data reflect responses of 120 "normal speaking white children from Central Utah. The use of the scale for inner city, large urban centers, does not seem appropriate." Cazden (1978) reports difficulties in interpreting CELI scores by stating:

... while the manual states clearly that the standardization sample was composed of white middle class children from the urban community, it does not discuss the problems encountered if the test is used with children outside that category.

There is an exorbitant amount of literature on the subject of oral language sampling analysis; however, the investigations have typically not included comparative studies on the basis of geographical differences. As indicated in several reviews, the need exists to provide normative data in a variety of geographical areas in order to evaluate critically and use the DSS as a measure of a child's syntactic, 
expressive language. 
CHAPTER III

METHODS AND PROCEDURES

Subjects

Forty normally developing children, ages 4.0 to 4.11 years, with 5 boys and 5 girls in each three-month interval, from the Portland, oregon metropolitan area served as subjects for the present investigation. The subjects were selected from the Helen Gordon Child Development Center, Fruit and Flower Day Care, Pencil Pals Preschool, and Kinderland Preschool.

In addition to meeting the age requirements, children met the following criteria:

1. white, living in monolingual homes where standard English of general American dialect is spoken;

2. from middle-class families as represented by education and occupational status (U.S. Dept. of Commerce, 1960);

3. normal hearing sensitivity as defined by audiometric screening at $20 \mathrm{dBHL}$ (unilateral);

4. no demonstrated or suspected physical or social delays as observed by the investigator and by teacher report; and

5. normal receptive vocabulary age as represented by a score for the appropriate chronological age according to the Peabody Picture Vocabulary Test (Dunn, 1965).

Permission form letters describing the purpose of the study were sent to parents of potential participants (Appendix B). Children with returned signed permission forms were 
screened for inclusion in the study.

\section{Instrumentation}

A portable Beltone 10D audiometer ANSI 1969, was used to conduct the audiometric screening of the subjects. A General Electric cassette tape recorder, Model $3-5145 \mathrm{~B}$ and an Electro-Voice microphone, Model $635 \mathrm{~A}$ were used to tape record the language samples.

The Peabody Picture Vocabulary Test (Dunn, 1965), Forms $A$ and $B$, an instrument created to provide an estimate of a child's receptive vocabulary, was used to establish normal receptive vocabulary age, consistent with chronological age. These forms were used in this study because Lee and Canter (1971) and Lee (1974a) utilized these measures in their original study. The Peabody Picture Vocabulary Test, Revised Edition (Dunn, 1981), Forms $L$ and $M$, were used to provide additional information regarding each child's receptive vocabulary age.

The DSS (Lee, 1974a) provides for analysis of a child's spontaneous tape recorded speech sample. It's development was based upon samples from children ages 2.0 to 6.11 years. The transcription of these samples is based upon the selection of fifty intelligible, complete, consecutive, non-echoic, different sentences. A sentence must contain a noun and verb in a subject-predicate relationship to be considered complete. The DSS yields weighted scores in eight grammatical categories: indefinite pronouns and/or modifiers, main verbs, 
personal pronouns, secondary verbs, negatives, conjunctions, interrogative reversals, and wh-questions (Appendix C). Within each classification, specific structures have been grouped in what has been found to be a general developmental order based upon published reports and observations by Lee (1974a). For example, the lowest score (score 1) is given to words which appear so early in children's language that they have often been noted as pivot words; the highest score (score 8) represents the most complex syntactic structures. A sentence point is added to the total response score if the entire sentence is correct in all respects, i.e., syntactically and semantically (Lee and Canter, 1971).

\section{$\underline{\text { Screening }}$}

Hearing screening and administration of the PPVT (Dunn, 1965), Forms A or B, were administered by the investigator upon receiving written parental consent for subject participation. The screening procedure was undertaken in a quiet room at the preschool site. Information regarding any physical social, and/or behavioral deficiencies was obtained by teacher report and investigator observation. Forty children meeting the criteria, within the specific age range, were included in this study.

\section{Language Sample Collection}

Each child met with the investigator for 20 to $60 \mathrm{~min}-$ utes and individual language samples were obtained at the 
preschool. Children using complete sentences, 50 or more percent of the time, were considered candidates.

A variety of sitting positions were utilized appropriate to the age and interests of the children (on the floor and at the table). The tape recorder and microphone were placed two feet away from the child, to ensure quality playback and minimum obtrusiveness. A piece of felt material was placed under the tape recorder to minimize any extraneous sounds resulting from handling of the materials.

Materials used to foster spontaneous speech included a doll family and plastic furniture, a transport truck with small cars in it, and a small barn with farm animals; these toys were presented to the children first. Pictures from the Game Oriented Activities for Learning (GOAL) (Karnes, 1972) were used in description tasks and a number of them were presented throughout the session. Pictures selected from the story, "The Three Bears" (Utley, 1950) were used to encourage retelling of the story.

The investigator used "open-ended" questions and comments, encouraging more than single utterances from the child. Additionally, sophisticated grammatical forms were used in order to provide an opportunity for the child to use them in his responses. Many of the child's responses were repeated in order to avoid confusions for later transcription which may have resulted from articulation errors or extraneous noise. 


\section{Language Sample Transcription}

Following the collection of language samples, the investigator transcribed the recordings into typed transcripts, adhering to specific instructions recommended by Lee (1974a) for separating and combining sentences (Appendix A) and for selecting the corpus for grammatical analysis (Appendix D). In Appenaix E, methods for transcribing the samples were adapted from Mathis (1970).

Following transcription of the samples, a corpus containing fifty complete, consecutive, different, intelligible, non-echoic sentences produced by the child, were selected and recorded into the DSS Record Form (Appendix F). Sentences selected contained a subject and a verb, but were not necessarily grammatically correct and complete.

\section{$\underline{\text { Scoring }}$}

The investigator was the collector and evaluator of all language samples obtained at the preschool site. The examiner viewed the film, "Developmental sentence Scoring" (Lee, 1974b) and successfully completed "Developmental Sentence Analysis," a course offered at Portland State University, in September, 1982. This course was taught by an associate professor holding a Certificate of Clinical competence in speechLanguage Pathology •

All rules for scoring the DSS described by Lee (1974a) were followed (Appendix G). Grammatical forms used by the 
child were assigned weighted, numerical scores. Credit was given only when the grammatical form met all the requirements of adult, standard English (syntactic, morphological, and semantic). A score of $I$ was added for each sentence which met these stipulations for the whole sentence. An attempt mark (-) was inserted in place of a numerical score when a structure was attempted but lacked a feature of standard English; a sentence point was not received.

After the fifty sentences were scored, the total sentence scores were added and divided by fifty to obtain a DSS score.

\section{Examiner Reliability}

Interjudge reliability was derived between the investigator and a Speech-Language Pathologist with a Certificate of Clinical Competence issued by the American Speech-LanguageHearing Association.

A fifty utterance language sample was chosen randomly and presented independently to the two judges for a DSS analysis. Interjudge reliability was .90. The two judges conducted a calibration session during which decisions were made about the analysis of various utterances. The remainder of the language analyses were then based on these decisions.

The investigator randomly selected twenty-five sentences from the sample utilized in the inter-judge comparison and scored this selection one week later, obtaining an intrajudge reliability of .92 . 


\section{Data Analysis}

DSS scores were computed for each subject's language sample. Descriptive statistics were subsequently applied to determine the mean weighted scores in the grammatical categories, the mean number of sentence points, standard deviations, ranges, and percentiles.

A comparison was then made between the descriptive statistics obtained by this investigation and that obtained in the Lee (1974a) study. Due to incomplete data provided by Lee and by Koenigsknecht (1974), it was necessary to establish a method for determining the variance of the standard deviation obtained by Lee in order to perform a comparative analysis. A pooled sum of squares was computed for both groups. A reconstruction of Lee's sum of squares was accomplished by squaring the S.D. of both groups and multiplying by forty $(N)$. A pooled sum of squares was then obtained by adding the sum of squares of both studies and dividing by the number of degrees of freedom (78). Two-tailed t-tests for independent means were applied to these scores to determine the significance of the differences between the two samples. 
CHAPTER IV

RESULTS AND DISCUSSION

\section{Results}

This study sought to compare DSS descriptive statistics as reported by Lee (1974a) and Koenigsknecht (1974) with those obtained in the geographical area of Portland, Oregon, for children ages 4.0 through 4.11 years. Individual language samples were elicited from 40 children who met all subject criteria as set by Lee. These language samples were transcribed and analyzed according to the DSS procedure as described.

The first research question posed was: what are the descriptive statistics of the DSS on language samples obtained in Portland, Oregon? The DSS mean and standard deviation of this sample were obtained and are represented in Table I by three-month age groups. The mean for the total sample, aged 4.0 to 4.11 was 7.27 with a standard deviation of 1.40 .

Table II shows the ranges and percentiles of the average DSS sentence score for the 40 children. The range of scores was 4.64 to 10.42 . The 10 th, 25 th, 50 th, 75 th, and 90 th percentile values for the overall DSS within each age group were computed (Frederick-Williams, 1979). Children 
with DSS scores of 5.52 or below fell into the 10 th percentile. Scores of 5.53 to 6.36 were grouped into the 25 th percentile. The 50th percentile represents scores from 6.37 to 7.08. Score of 7.09 to 8.10 fell in the 75 th percentile. Children with DSS scores of 8.11 to 9.14 were represented in the 90 th percentile.

The mean weighted developmental scores on the DSS component grammatical categories are represented in Tables III and IV. The mean scores, per category are: indefinite pronouns, 42.70 with a mean of 1.45 ; personal pronouns, 69.40 with a mean of 1.36 ; main verbs, 101.07 with a mean of 1.87; secondary verbs, 25.10 with a mean of 3.33 ; negatives, 23.70 with a mean of 7.00 ; conjunctions, 37.40 with a mean of 3.88 ; interrogative reversals, 1030 with a mean of 3.17 ; and whquesitons, 12.60 with a mean of 3.86 . The mean number of sentence points for the 40 subjects was 42.10 .

Tables I through IV display the descriptive data obtained and provide the answer to the first research question this study sought to answer.

The second question posed by this study was: does a significant difference exist between the original results compliled by Lee (1974a) and Koenigsknecht (1974) in the Midwest and that obtained in Portland, Oregon. In Table $\mathrm{V}$ it can be seen that results of a two-tailed t-test of independent means indicate a statistically significant difference beyond the .05 level of confidence between the means for the two groups with Lee's sample from the Midwest obtaining a 
TABLE I

DSS MEANS AND STANDARD DEVIATIONS OF FORTY SUBJECTS BY THREE-MONTH

AGE GROUPS (PORTLAND, OREGON)

\begin{tabular}{llcr}
\hline Age Group & $\mathrm{N}$ & Mean DSS & S.D. \\
\hline $4.0-4.2$ & 10 & 6.83 & 1.75 \\
$4.3-4.5$ & 10 & 6.82 & .84 \\
$4.6-4.8$ & 10 & 7.52 & 1.02 \\
$4.9-4.11$ & 10 & 7.90 & 1.64 \\
$4.0-4.11$ & 40 & 7.27 & 1.40 \\
\hline
\end{tabular}

TABLE II

RANGE AND PERCENTILES OF DSS SCORES

FOR FORTY SUBJECTS BY THREE-

MONTH AGE GROUPS

\begin{tabular}{lccccccr}
\hline \hline \multirow{2}{*}{ Age Group } & N & Range & \multicolumn{5}{c}{ Percentiles } \\
& & & 10th & 25 th & 50 th & 75 th & 90 th \\
\hline $4.0-4.2$ & 10 & $4.64-9.28$ & 4.64 & 5.36 & 5.98 & 8.74 & 8.80 \\
$4.3-4.5$ & 10 & $5.58-8.10$ & 5.58 & 6.34 & 6.76 & 7.36 & 8.10 \\
$4.6-4.8$ & 10 & $6.44-9.30$ & 6.44 & 6.70 & 7.08 & 8.66 & 8.70 \\
$4.9-4.11$ & 10 & $5.52-10.42$ & 5.52 & 6.66 & 7.86 & 9.14 & 10.20 \\
& & & & & & & \\
$4.0-4.11$ & 40 & $4.64-10.42$ & 5.52 & 6.36 & 7.08 & 8.10 & 9.14 \\
\hline
\end{tabular}




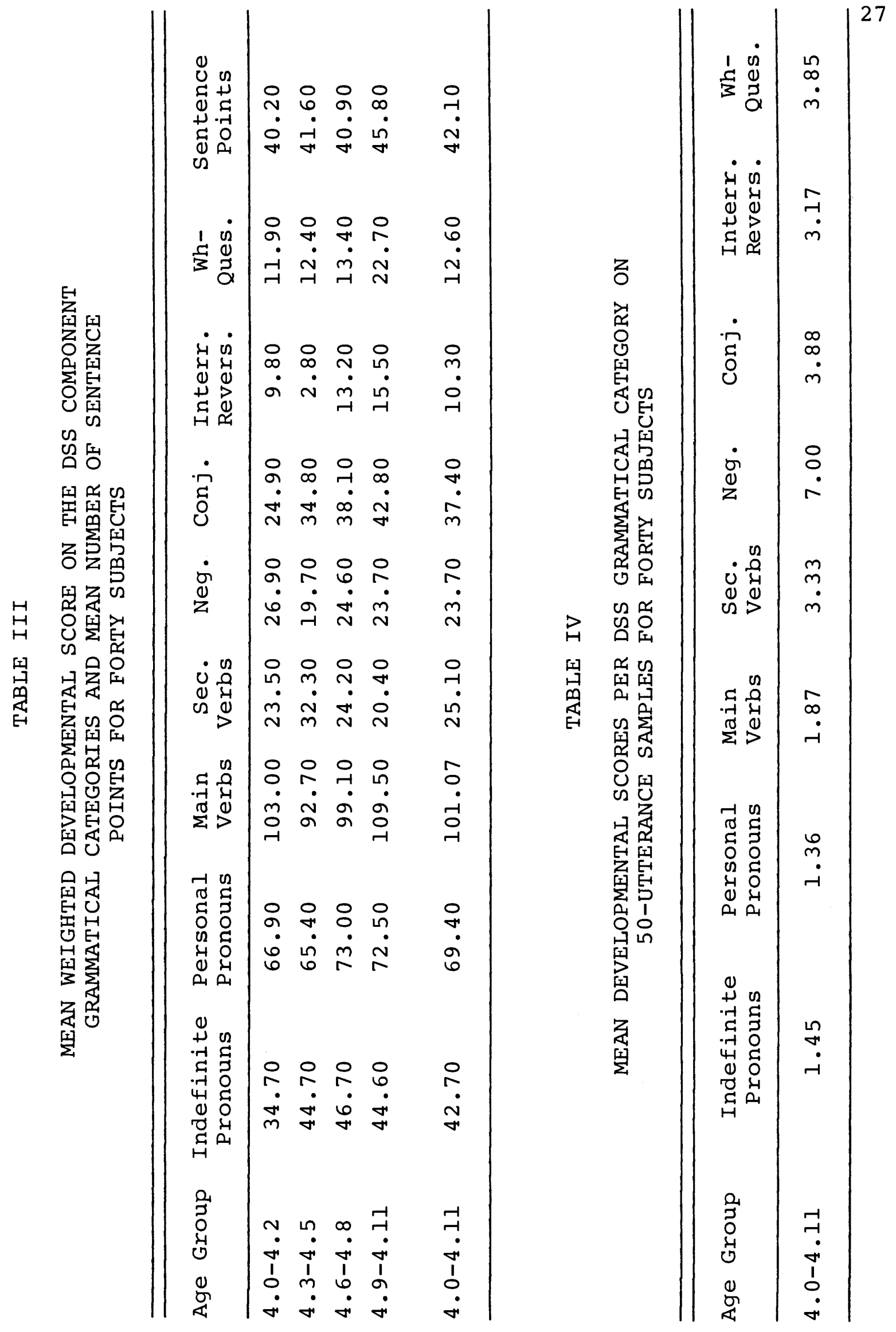


TABLE V

COMPARISON OF DSS MEANS AND STANDARD DEVIATIONS

OBTAINED IN THE MIDWEST AND PORTLAND, OREGON

\begin{tabular}{llllll}
\hline $\begin{array}{l}\text { Geographical } \\
\text { Location }\end{array}$ & Mean & S.D. & df & test & $p$ \\
\hline Midwest (1974) & 8.04 & 1.64 & 78 & 2.238 & $<.05$ \\
Portland (1984) & 7.27 & 1.40 & & & \\
\hline
\end{tabular}

higher DSS mean score than the present Portland sample. Comparative data obtained in the Midwest and in Portland, Oregon are presented below. Tables VI and VII provide information on the mean "weighted" developmental score (the sum of the weighted scores for a given DSS component category) and the mean developmental score per DSS grammatical category for the two studies. Koenigsknecht (1974) did not report the standard deviation per category, so it is not possible to determine if a statistically significant difference exists between mean developmental scores. By visual inspection, however, it would appear that children in the Portland study used higer level negatives, interrogative reversals, and whquestions than those children in the Midwest; indefinite pronouns and personal pronouns were used more often by children in the Midwest study, with a difference score of 14.1 and 36.1 respectively.

In examining the range and percentiles of DSS scores 
TABLE VI

COMPARISON OF MEAN WEIGHTED DEVELOPMENTAL SCORES

ON THE DSS COMPONENT GRAMMATICAL CATEGORIES

AND MEAN NUMBER OF SENTENCE POINTS

FOR FORTY SUBJECTS BY GEOGRAPH-

ICAL LOCATION

\begin{tabular}{lrcc}
\hline \hline $\begin{array}{l}\text { Grammatical } \\
\text { Category }\end{array}$ & $\begin{array}{c}\text { Midwest } \\
(1974)\end{array}$ & $\begin{array}{c}\text { Mean } \\
\text { Portland } \\
(1984)\end{array}$ & Difference \\
\hline Indefinite Pronouns & 56.80 & 42.70 & -14.1 \\
Personal Pronouns & 105.53 & 69.40 & -36.13 \\
Main Verbs & 108.90 & 101.07 & -7.2 \\
Secondary Verbs & 25.08 & 25.01 & +.02 \\
Negatives & 17.40 & 23.70 & +6.3 \\
Conjunctions & 36.25 & 37.40 & +1.15 \\
Interrogative Reversals & 7.32 & 10.30 & +2.98 \\
Wh-Questions & 6.40 & 12.60 & +6.2 \\
Sentence Point & 37.15 & 42.10 & +4.95 \\
& & & \\
\hline
\end{tabular}

(Table VIII), the present study reflects a narrower range (4.64-10.42) than the Lee (1974a) study (4.86-12.95). Lower DSS scores at the 10 th, 25th, 50th, 75th, and 90 th percentiles were obtained as well. Table IX reflects the assignment of the 40 subjects from this study, to a percentile using Lee's "Norms for Developmental Sentence Scoring" (1974). This was done by plotting the position of each subject's score on the DSS norm chart. The same subjects' scores were then assigned a percentile ranking based upon the DSS scores within the sample in the Portland area. 
TABLE VII

COMPARISON OF MEAN DEVELOPMENTAL SCORES

PER DSS GRAMMATICAL CATEGORY BY

GEOGRAPHICAL LOCATION

\begin{tabular}{lcc}
\hline Grammatical Category & $\begin{array}{c}\text { Midwest } \\
(1974)\end{array}$ & $\begin{array}{c}\text { Mean } \\
\text { Portland, Oregon } \\
(1984)\end{array}$ \\
\hline Indefinite Pronouns & 1.93 & 1.45 \\
Personal Pronouns & 2.07 & 1.36 \\
Main Verbs & 2.02 & 1.87 \\
Secondary Verbs & 3.33 & 3.33 \\
Negatives & 5.14 & 7.00 \\
Conjunctions & 3.77 & 3.88 \\
Interrogative Reversals & 2.26 & 3.17 \\
Wh-Questions & 1.96 & 3.85 \\
\end{tabular}

TABLE VIII

COMPARISON OF RANGE AND PERCENTILES OF DSS

SCORES FOR THE MIDWEST AND PORTLAND, OR.

FOR CHILDREN 4.0 THROUGH 4.11 YEARS

\begin{tabular}{lccccccc}
\hline \hline $\begin{array}{l}\text { Geographical } \\
\text { Location }\end{array}$ & $N$ & Range & 10th & 25th & 50th & 75th & 90 th \\
\hline Midwest & 40 & $4.86-12.94$ & 6.01 & 6.97 & 8.04 & 9.10 & 10.06 \\
Portland & 40 & $4.64-10.42$ & 5.52 & 6.36 & 7.08 & 8.10 & 9.14 \\
\hline
\end{tabular}

Discussion

The DSS mean obtained in the present study differed 
TABLE IX

COMPARISON OF NUMBER OF SUBJECTS PER PERCENTILE RANK USING MIDWEST NORMS AND PORTLAND, OREGON NORMS

\begin{tabular}{|c|c|c|c|c|c|c|c|c|}
\hline \multirow{2}{*}{$\begin{array}{c}\text { Geographical } \\
\text { Location }\end{array}$} & \multirow[t]{2}{*}{ Age } & \multirow[t]{2}{*}{$\mathrm{N}$} & \multicolumn{5}{|c|}{ Percentiles } & \multirow{2}{*}{90 th } \\
\hline & & & -10 th & 10 th & & 50 th & 75 th & \\
\hline $\begin{array}{l}\text { Midwest } \\
(1974)\end{array}$ & $4 \cdot 0-4.2$ & 10 & 2 & 2 & 1 & 2 & 0 & 3 \\
\hline $\begin{array}{l}\text { Portland } \\
(1984)\end{array}$ & & & 0 & 3 & 2 & 0 & 4 & 1 \\
\hline Midwest & $4 \cdot 3-4 \cdot 5$ & 10 & 0 & 2 & 4 & 2 & 2 & 0 \\
\hline Portland & & & 0 & 0 & 4 & 3 & 3 & 0 \\
\hline Midwest & $4 \cdot 6-4.8$ & 10 & 0 & 0 & 3 & 5 & 2 & 0 \\
\hline Portland & & & 0 & 0 & 0 & 5 & 4 & 1 \\
\hline Midwest & $4.9-4.11$ & 10 & 1 & 1 & 3 & 2 & 1 & 2 \\
\hline Portland & & & 0 & 1 & 0 & 3 & 4 & 2 \\
\hline \multicolumn{9}{|l|}{ Combined } \\
\hline Midwest & $4.0-4.11$ & 40 & 3 & 5 & 11 & 11 & 5 & 5 \\
\hline Portland & & & 0 & 4 & 6 & 11 & 15 & 4 \\
\hline
\end{tabular}

significantly $(p<.05)$ from that reported by Lee and Koenigsknecht (1974). The following discussion will begin with a focus on the variables which may account for the differences between the two samples.

One variable that may have accounted for the differences in the results of these two studies is socio-economic level; however, the two samples were drawn from similar 
socio-economic backgrounds. In determining "middle-income" eligibility, Lee and Canter (1971) reported the occupation rating as being the "most powerful single status characteristic for assigning social class placement (Warner, Meeker, and Eells, 1949)." The present study used both an occupational and educational rating in assigning placement. All subjects' parents were within the ranges of 45 to 90 , with a mean of 76.25 for the occupation scale, and 67 to 98 , with a mean of 84.87 for the education scale (U.S. Dept. of Commerce, 1960). Both ratings were within "middle-income" criteria; either the education or occupation rating could have been used solely. Lee chose to include two subjects below the middle income range on the Warner scale and one who was considered "unclassifiable" in the 1974 study; two subjects in the 1971 study also were included who were not considered within the "middle-income" range.

All subjects demonstrated normal receptive vocabulary knowledge with PPVT scores ranging from 85 to 115 . In selecting the subjects for the present study, Forms $A$ and $B$ of the PPVT (Dunn, 1965) were used to establish normal receptive vocabulary age, in order to replicate Lee's procedure. By way of ancilary information, the PPVT-R (Dunn, 1981) also was administered to determine what extent those same subjects would be included or excluded from the study, had the revised edition been used rather than the original. Standard scores for Form I were consistent with those of Form A, i.e., none of the subjects would have been excluded from the study. Six 
subjects would have been excluded from the study, using Form M, due to the standard scores exceeding the acceptable range of 85 to 115 . Two children scored below 85 while 4 children scored above 115 .

Differences in the results of the two studies do not appear to be attributable to the particular stimulus materials used. Materials used in the present study were similar to those used in the Lee (1974a) study, with the exception of the story-action pictures by Robinson, Monroe, and Artley (1962 a, b, c). Due to the unavailability of these pictures, this investigator substituted pictures from the Game oriented Activities for Learning (GOAL) (Karnes, 1972). It appears unlikely that these materials accounted for differences in the children's utterances; in most cases, the language sample corpus was obtained when the children were playing with the toys and retelling the story "The Three Bears" (Utley, 1950). All materials were presented in the order suggested by Lee, i.e., toys, story-action pictures, and pictures designed to encourage retelling of the story.

Smith (1970) has reported that the presence of other objects in the room may have an effect on a child's verbal utterances. Thirty percent of the language samples were collected in a room that did not contain other toys or materials. Examination of the data for these subjects revealed a mean DSS score of 7.44 , slightly above the mean (see Table I). Thus, it appears that the presence of other toys and materials in the playroom did not negatively affect the DSS scores 
in this study.

It is unlikely that variation in the elicitation of the utterances was responsible for the differences in the scores between the two studies. In eliciting the language sample, a warm conversational climate conducive to eliciting complete sentences, fulfilling the subject-verb requirements was established. The investigator adhered to guidelines provided by Lee in eliciting responses. The examiner interacted with the toys, talked about the pictures, and used high level grammatical forms, thus encouraging the subjects to use these forms in response.

Variation in the transcription of the samples is not a likely variable affecting the results of the study. In transcribing the language samples, great care was taken in following directions adapted from Mathis (1970) (Appendix E) and Lee (1974a) (Appendices $A$ and D). Remarks and questions used by the examiner were designated as recommended by Siegel

(1962) in order to avoid any confusion with utterances. The quality of the taped language sample presented no difficulty in analysis. Lee recommended using the last fifty utterances of the language sample for analysis in order to consider the effects of "warm up" and general adjustment to the conversational setting; this was accomplished in 26 of the 40 cases. Samples from the remaining 14 children included only fifty to sixty utterances, so those utterances were the only ones available for analysis. In examining the data, those language samples in which the last fifty utterances were used did 
not favor better grammatical usage than the more limited samples.

Description of the scores in the specific grammatical areas can contribute to the discussion of the differences found in the two studies. The scores in the grammatical categories in the two studies varied considerably (see Table VI and VII). The question forms used as models by the examiner may have had an effect on the high scores in the negative, interrogative reversal, and wh-question categories. For example, the interviewer's questions such as, "Why won't the car go?" and "Is the farmer driving?" may have provided sufficient models for the children to use these forms, as well. Data in Table VI also reveal a greater mean developmental score for the "sentence point" category in the Portland study. The examiner's use of open-ended questions, such as "What happened?" or "What next?" may account for the differences in scores.

Examination of the scores for the indefinite pronoun category indicate a lower mean score for the present study when compared to the mean score obtained in the Midwest. Pivot words such as, "it," "this," and "that" were most often used (score of l) as well as quantity words, such as, "some" and "more" (score of 3). Negative pronouns (score of 4) and later developing pronouns, such as, "everything," "each," and "several" (score of 7) were used by only 17 children. The examiner modeled high level indefinite pronouns, such as, "The boy likes to play with each block by himself." This, 
however, did not always elicit the use of later developing pronouns.

In examining the low developmental score in the personal pronoun category, the first and second person pronouns were used most often, i.e., "me" and "you," receiving a score of 1. Plural pronouns (score of 3) require a consideration of person, number, and case and were used by 93 percent of the children. Reflexive and wh-pronouns (score of 5 and 6) were used by 4 children. The limited use of more developmentally mature expression using pronouns accounts for the lower developmental score for this category. It is interesting to note that, had the personal pronoun category not been included in the comparison of mean weighted developmental scores in the grammatical categories, the differences in results would have been much less. Although it is not possible to determine this difference statistically, by inspection of Table VI, it can be seen that the lower score obtained in Portland probably contributed substantially to the lower overall mean (7.27). The depressed score in the personal pronoun category may have resulted from slight variations in stimulus materials and/or elicitation of responses. The examiner, however, did provide modeling of higher level use of personal pronouns and utilized all procedural guidelines as suggested by Lee (1974a) in obtaining the samples.

The mean weighted developmental score in the negative category was greater than that obtained by Lee (1974a). A score of 4 was given to the negative forms "can't" and 
"don' $t$," these forms were used by 87 percent of the children. A score of 7 was applied to all other negatives and was used in 31 of the 40 samples.

Children in the present study also used highly sophisticated forms of the interrogative reversal. Not only did 80 percent of the children use the earliest form of the interrogative reversal with the copula "is," but, 55 percent also used the reversal of the obligatory "-do," "-does," or "-did" (score of 6). The examiner modeled the interrogative reversal with such questions as "Couldn't the man get in the truck?" which may, in part, account for the higher score in this category.

Forty-eight percent of the children (19) in this study used the wh- words "when" and "how" (score of 5), accounting for a mean weighted developmental score of 12.60 as compared to a score of 6.40 reported by Lee (1974a). This is surprising, since the concepts of time and manner are often slower to develop than the concepts of person, thing, action, place, quantity, etc. Eleven of the 40 children (28 percent) used wh-questions implying purpose or causality, i.e., "why" (score of 7).

Comparison of percentile ranking also may be used in discussing differences between the two studies. Inspection of Table IX reveals that 3 subjects from the present study, would have been considered below the 10th percentile based upon Lee's norms. These subjects, however, would have been judged to be at the loth percentile based upon norms for 
their given population. Using Lee's norms, a child below the loth percentile would be considered a candidate for further evaluation or possible remedial training. Using the norms obtained in this specific geographical area, however, that same child might be judged to be at the loth percentile and the speech-language clinician's concern for intervention might be lessened. Further inspection reveals a spread of percentile scores for the Lee study due to the larger sum of squares and standard deviation for that study. In the present investigation, there appears to be more of a "clustering" of percentile scores towards the 25th and 50th percentiles.

In providing ancillary information, visual inspection reveals that the mean developmental scores on the DSS component grammatical categories do not reflect a developmental trend, i.e., the 4.9 to 4.11 age group did not necessarily use more mature language or receive a higher weighted mean score than the younger age groups. The grammatical categories which did display a quantifiable and progressive increase in syntactic development were: conjunctions, interrogative reversals, wh-questions and the sentence point.

By way of summary, the mean DSS score for this investigation, using Developmental Sentence Scoring, differs significantly from the mean DSS score reported by Lee (1974a) and Koenigsknecht (1974) for four-year olds. Although it is not possible to determine the statistical differences of the ranges, percentiles, and mean developmental scores per grammatical 
category of the two studies, quantifiable as well as qualifiable differences can be observed by means of visual inspection of the data. The differences in scores do not appear to be attributable to the variables described in the literature, i.e., subject selection or variations in the elicitation or transcription of language samples. Due to the differences exhibited in the scores per grammatical category, it would appear feasible that the examiner's method of modeling and/ or prompting may have been a contributory factor in explaining the differences obtained in the two studies. Geographical location, however, was the only factor systematically manipulated in replicating the Lee study and it appears that this variable could feasibly account for the difference in the data. If this is true, it is essential for the speech-language clinician to use the DSS norms with caution if practicing in an area other than the Midwest. It also is imperative that the speech-language practitioner establish his or her own norms for the specific geographical area prior to further evaluation or diagnosis. 


\author{
CHAPTER V \\ SUMMARY AND IMPLICATIONS
}

\title{
Summary
}

Oral language sampling and analysis are tools available to the speech-language clinician, which are often helpful in obtaining information regarding the development of expressive language in children. In the past, a child's language has been judged to be mature based upon the length of the utterance (MLR, MLU) and/or the grammatical complexity (SCS, LCI, DSS) •

The purpose of this investigation was to replicate the study conducted by Lee and Canter (1971) and Lee (1974a) to determine if a significant difference among the scores in the two studies existed due to geographical location, and to initiate the establishment of norms for the Portland, Oregon geographical area. Forty children, selected on the basis of chronological age ( 4.0 to 4.11 years), normal receptive vocabulary skills, normal hearing, and a monolingual background, participated as subjects. A language sample of fifty utterances was elicited from each child and analyzed according to the DSS procedure.

DSS means, standard deviations, percentiles, range of the average score, mean weighted developmental score for each 
grammatical category, and mean number of DSS utterances earning a sentence point were compiled. A t-test analysis was conducted to determine if a difference exists between the means of the scores for the two geographical locations.

A significant difference resulted between the mean scores obtained in the Midwest and in Portland, oregon. The results indicate that a statisitically significant difference in the mean DSS score exists $(p<.05)$ and may be attributable to differences in the geographical location in which the scores were obtained. Differences in scores do not appear to be attributable to variables in subject selection, i.e., socio-economic background, receptive language vocabulary scores, etc. Although slight variation in the examiner's form of elicitation and use of stimulus materials may possibly explain some of the differences found in the grammatical categories, it appears an unlikely possibility that this variation could account for the statistically significant difference found between the mean DSS scores of the two studies. In addition, the differences do not appear to be the result of stimulus materials or transcription methods used.

The norms compiled by Lee (1974a) in the Midwest, differ significantly from those obtained in this study, conducted in Portland, Oregon. It appears likely that score differences in other geographical areas may exist as well. In order to conduct a thorough and competent evaluation of a child's expressive language abilities, the data from this investigation reflect the need for the speech-language 
clinician to use the DSS norms cautiously and/or to establish norms specific to a geographical region.

\section{Clinical Implications}

This investigation has demonstrated that geographical location is a plausible variable accounting for the statistically significant difference between obtained DSS scores. The results indicate that the norms established by Lee (1974a) in the Midwest are higher than those of the Portland, Oregon area. Therefore, in using Lee's normative data, a child in Portland may be evaluated as functioning within a lower percentile in expressive language; in some cases, a child may be assessed as "language delayed," using the norms developed in the Midwest, when, in fact, he may be functioning at the loth or 25 th percentile in a different locale. This investigation substantiates other authors who caution speech-language practitioners in interpreting assessment norms compiled in communities other than their own (Lyman, 1965; Butler, 1972; Cazden 1978).

This investigation also addresses the role of the speech-language clinician as one of a researcher. The results of this study, particularly the percentile tables, address the discrepancy in normative data and the need for each clinician to be aware of these differences in his/her particular geographical area. If norms are unavailable, it would appear to be the responsibility of the speech-language 
clinician to establish them for the specific geographical region.

Clinically, the DSS norms compiled by Lee (1974a) may be used to judge a child's progress throughout the period of clinical teaching and also to aid in determining when to dismiss him from remedial teaching. For diagnostic purposes, however, the DSS could be used as part of an assessment battery; Lee has cautioned that a DSS score when compared with the mean of a child's chronological age group, yields only limited and gross information about language development.

\section{Research Implications}

Further investigations in a variety of geographical areas, using the DSS procedure is indicated. Additional studies conducted on the East coast, the northern part of the United States and the southern regions, would assist in determining the extent to which geographical location affects DSS results and/or to what extent other variables are influential.

A study conducted in Portland, using the same age group would aid in determining if other variables influenced the results, i.e., subject-examiner interaction, the form or use of modeling and prompting, variations in transcription, etc. Replication of this study in the Portland, Oregon area, with different age groups is also indicated. The present investigation obtained and analyzed results for 4.0 through 4.11 year old children. The performance of children, ages 
2.0 through 6.11 would contribute enormously to the validity of this study as well as establish more complete normative data for the Portland area, using Developmental Sentence Scoring. 


\section{SELECTED BIBLIOGRAPHY}

AHMED, S. E. Linguistic analysis of children's speech:

Effects of stimulus media on elicited samples. Unpublished Master's thesis, Kansas State University, 1973. In S. Barrie-Blackley, C. Musselwhite and S. Rogister, Clinical oral language sampling. Danville, IL: The Interstate Printers and Publishers, Inc., 1978.

BARRIE-BLACKLEY, S. MUSSELWHITE, C. , and ROGISTER, S. Clinical oral language sampling. Danville, IL: The Interstate Printers and Publishers, Inc., 1978.

BETTS, E.A. An evaluation of certain techniques for the study of oral composition. Research Studies in Elementary School Language, $1934, \overline{9}, 7-35$. In S. BarrieBlackley, C. Musselwhite, and S. Rogister, Clinical oral language sampling. Danville, IL: The Interstate Printers and Publishers, Inc., 1978.

BLOOM, L. Language development: Form and function in emerging grammars. Cambridge, Mass.: MIT Press, 1970.

BROWN, R. The development of wh-questions in child speech. Journal of Verbal Learning and Verbal Behavior, 1968, 7, 279-290.

BROWN, R. A first language: The early stages. Cambridge, Mass.: Harvard University Press, 1973.

BROWN, R. and FRASER, C. The acquisition of syntax. Child Development, 1964, Monograph 29, 43-79.

BUTLER, K. Review of verbal language development scale. In O. Buros (Ed.), Seventh mental measurements yearbook. Hyland Park: Gryphan, 1972.

CARROW, E. A test using elicited imitation in assessing grammatical structure in children. Journal of Speech and Hearing Disorders, $1974 \mathrm{a}, 39,43 \overline{7-444}$.

CARROW, E. Carrow elicited language inventory. Austin, Texas: Learning Concepts, 1974b.

CAZDEN, C.B. Review of the CELI. In O. Buros (Ed.), Eighth mental measurements yearbook. Hyland Park, NJ: Gryphan, 1978. 
CHOMSKY, N. Syntactic structures. The Hague: Mouton, 1957.

CHOMSKY, N. Aspects of the theory of syntax. Cambridge, Mass.: MIT Press, 1965.

COWAN, A.A., WEBER, J., HODDINOTT, B.A., and KLEIN, J. Mean length of spoken response as a function of stimulus, experimenter, and subject. Child Development, 1967, $38,191-203$.

DUNN, L. Peabody Picture Vocabulary Test. Circle Pines, MN: American Guidance Service, 1965.

DUNN, L. Peabody Picture Vocabulary Test (Rev. ed.). Circle Pines, MN: Holt, Rinehart, and Winston, 1981.

FREDERICK-WILLIAMS. Reasoning with statistics (2nd ed.). New York: Holt, Rinehart, and Winston, 1979.

GEERS, A., and MOOG, J. Syntactic maturity of spontaneous speech and elicited imitations of hearing-impaired children. Journal of Speech and Hearing Disorders, $1978,43,3 \overline{80-391 .}$

HASS, W.A. and WEPMAN, J.M. Constructional variety in the spoken language of school children. The Journal of Genetic Psychology, 1973, 122, 297-308.

JOHNSON, D.L. The influence of social class and race on language test performance and spontaneous speech of preschool children. Child Development, 1974, 45, 517-521.

JONES, P.A. and MCMILLAN, W.B. Speech characteristics as a function of social class and situational factors. Child Development, 1973, 44, 117-121.

KARNES, M. Game oriented activities for learning. "Scenes around us." Springfield, Mass.: Milton Bradley Co., 1972 .

KLIMA, E. and BELLUGI, U. Syntactic regularities in the speech of children. In J. Lyons and R.J. Wales (Eds.), Psycholinguistic Papers. Edinburgh: Edinburgh Univ., 1966.

KOENIGSKNECHT, R. Statistical information on developmental sentence analysis. In L. Lee Developmental Sentence Analysis. Evanston, IL: Northwestern Univ. Press, 1974.

KRAMER, C., JAMES, S., and SAXMAN. J. A comparison of language samples elicited at home and in the clinic. Journal of Speech and Hearing Disorders, $1979,44,321-330$. 
LEE, L. Developmental Sentence Analysis. Evanston, IL: Northwestern Univ. Press, 1974a.

LEE, L. "Developmental Sentence Scoring" (film). 20 min., color. Northwestern University Film Library, 1974b.

LEE, L. and CANTER, S. Developmental sentence scoring: A clinical procedure for estimating syntactic development in children's spontaneous speech. Journal of Speech and Hearing Disorders, 1971, 36, 315-340.

LEONARD, L.B. What is deviant language? Journal of Speech and Hearing Disorders, $1972,37,427-446$.

LONGHURST, T. and FILE, J. A comparison of developmental sentence scores from headstart children collected in four conditions. LSHSS, 1977, 8, 54-64.

LONGHURST, T.M. and GRUBB, S. A comparison of langauge samples collected in four situations. LSHSS, 1974, 5, $71-78$.

LYMAN, H. Review of the PPVT. In O. Buros (Ed.) Sixth mental measurements yearbook. Hyland Park: Gryphan, 1965 .

MATHIS, J. Comparison of amounts of verbal responses elicited by a speech pathologist in the clinic and a mother in the home. Unpublished Master's thesis, Portland State University, 1970 .

MCCARTHY, D.A. The language development of the pre-school child. University of Minnesota, Institute of Child Welfare, Monograph Series IV. Minneapolis, MN: Univ. of Minn. Press, 1930.

MCCARTHY, D.A. Language development in children. In L. Carmichael (Ed.), Manual in child psychology. New York: Wiley, 1954 .

MCNEILL, D. Developmental psycholinguistics. In I. Smith and G.A. Miller (Eds.), The genesis of language. Cambridge, Mass.: MIT Press, 1966.

MCNEILL, D. The acquisition of language: The study of Developmental psycholinguistics. New York: Harper and Row, 1970 .

MENYUK, P. Syntactic rules used by children from preschool through first grade. Child Development, 1964, 35, 533546 . 
MINER, L.E. Scoring procedures for the length complexity index: A preliminary report. Journal of Communication Disorders, 1969,2 , 224-240.

MINIFIE, F.D., DARLEY, F.L., and SHERMAN, D. Temporal reliability of seven language measures. Journal of speech and Hearing Research, 1963, 6, 139-147.

MINTUN, S. An evaluation of three stimulus media for eliciting verbal language samples from educable mentally handicapped children. Unpublished Master's thesis, Eastern Illinois Univ., 1968. In S. Barrie-Blackley et al., Clinical oral language sampling. Danville, IL: The Interstate Printers and Publishers, Inc., 1978.

MUELLER, E., The maintenance of verbal exchanges between young children. Child Development, 1972, 43, 930-938.

NICE, M. Length of sentences as a criterion of a child's progress in speech. Journal of Educational Psychology, $1925,16,370-379$.

ROBINSON, H.M., MONROE, M., and ARTLEY, A.S. Before we read. Chicago, IL: Scott Foresman. Pp. 1, 2, 4, 10, 11, $14,16.1962 \mathrm{a}$.

ROBINSON, H.M., MONROE, M., and ARTLEY, A.S. We read pictures. Chicago, IL: Scott Foresman. $\overline{\mathrm{Pp} .1,2}$. 1962b.

ROBINSON, H.M., MONROE, M., and ARTLEY, A.S. We read more pictures. Chicago, IL: Scott Foresman. Pp. 4, 16, 20, 28. 1962C.

SHATZ, M. and GELMAN, R. The development of communication skills: Modifications in the speech of young children as a function of listener. Monographs of Society for Research in Child Development, 1973, 38, No. 152 .

SIEGEL, G.M. Interexaminer reliability for mean length of response. Journal of Speech and Hearing Research, 1962, $5,91-95$.

SMITH, D.R. The effect of four common patterns and sex on length of verbalization in speech of four year old children. (Final Report, Office of Economic Opportunity, Contract No.: B99-4980). Buffalo, NY, 1970. In S. Barrie-Blackley et al., Clinical oral language sampling. Danville, IL: The Interstate Printers and Pub1ishers, Inc., 1978. 
TEMPLIN, M.C. Certain language skills in children. Minneapolis, MI: Univ. of Minnesota Press, 1957.

TYACK, D. Language sampling analysis and training. Palo Alto, CA: Consulting Psychologists Press, 1974.

UNITED STATES DEPARTMENT OF COMMERCE. Methodology in scores of socio-economic status, 1960 .

UTLEY, J. What's its name? "The three bears." Urbana, IL: Univ. of Illinois Press, 1950.

VALENCIANO, M. Developmental sentence scoring sample size comparison. Unpublished Master's thesis, Portland State University, 1981.

WARNER, W.L., MEEKER, M., and EELLS, K. SOcial class in America. Chicago, IL: Science Research Associates, 1949.

WATSON, B. Three variations of verbal stimuli with a play house task for language sample elicitation. Unpublished Master's thesis, Univ. of North Carolina at Chapel Hill, 1976. In S. Barrie-Blackley et al., Clinical oral language sampling. Danville, IL: The Interstate Printers and Publishers, Inc., 1978.

WELKOWITZ, J., CARIFFE, G., and FELDSTEIN, S. Conversational congruence as a criterion of socialization in children. Child Development, 1976, 47, 269-272. 


\section{APPENDIX A}

\section{RULES FOR SEPARATING AND COMBINING SENTENCES}

1. Interjections and nouns in direct address do not carry a DSS score, so they do not have to be separated out.

2. Question markers must be noted because questions receive a DSS score.

3. Imperative interjections, "look," "lookit," and "see" and sentence tags, "you know," "I think," "I guess," etc. are separated out and given sentence status.

Concerning Conjunctions :

1. Sentences which begin with conjunctions are counted as complete sentences, but the initial conjunction is not scored.

2. Only one "and" conjunction per sentence is allowed when the "and" connects two independent clauses.

3. The conjunction "and" used in a series, a compound subject, or a compound predicate does not require the sentence to be broken up.

4. Internal conjunctions other than "and" do not require a sentence to be broken up.

5. At the clinician's discretion, the rules for "and" may be applied to any other over-used conjunction.

If a child's sample contains both a pre-sentence structure and a complete sentence, a separation is made if the sentence is an independent clause; the fragment and the conjunction would be deleted and only the independent clause would be scored. For example, "Over there but it's too far." "...it's too far." would be scored. 
APPENDIX B

PERMISSION FORM

I agree to let my child

participate as a subject in the study entitled "A Comparative Study of Developmental Sentence Scoring Normative Data."

This study is carried out by Kathie McCluskey under the supervision of Mary Gordon, thesis director, speech and Hearing Sciences Program, Portland State University.

The purpose of the study is to compare scores obtained from language samples in the Portland area to scores used as normative data collected in the Midwest.

There are no risks or dangers inherent in the procedures of the study. My child will be given a hearing screening, hearing vocabulary test, and then will simply participate in conversations with Kathie McCluskey at the preschool site. I am free to withdraw my child from the study at any time.

Signature of Parent/Guardian

\section{Date}

Birthdate of Child $\overline{\mathrm{MO}}^{-} \overline{\mathrm{Day}}-\overline{\mathrm{Yr} \cdot}$

The following information will be helpful in describing the sample:

OCCUPATION OF PRIMARY WAGE EARNER:

YEARS OF EDUCATION OF PRIMARY WAGE EARNER:

Please return this form with your child tomorrow, indicating your approval. If you have any questions, leave a message with the director at the preschool and I will return your call. Thank you. 


\section{DEVELOPMENTAL SENTENCE SCORING CATEGORIES AND REWEIGHTED SCORES}

\begin{tabular}{|c|c|c|c|c|}
\hline & 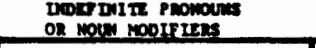 & PMSOML Promouns & minveme & stconearir venus \\
\hline 1 & 18, chto, that & 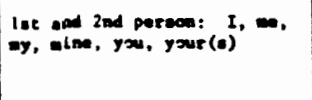 & 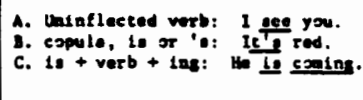 & \\
\hline 2 & & $\begin{array}{l}\text { 3rd perresa: he, his, his } \\
\text { the, her, here }\end{array}$ & 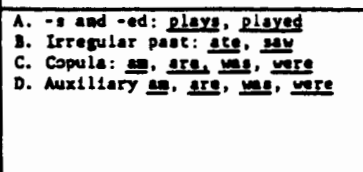 & 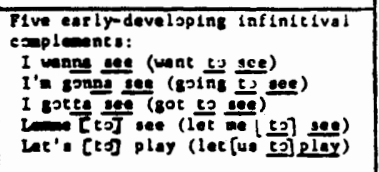 \\
\hline 3 & 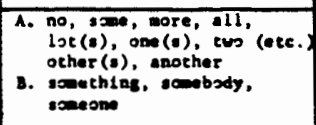 & $\begin{array}{l}\text { A. Pluralo: w, us, aur(o) } \\
\text { they, then, the ir } \\
\text { o. these, those }\end{array}$ & & 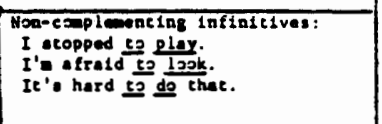 \\
\hline 4 & 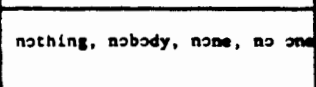 & & 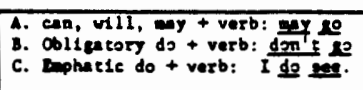 & 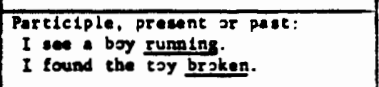 \\
\hline 5 & & 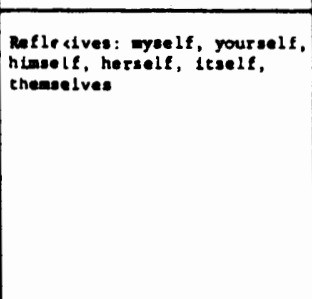 & & 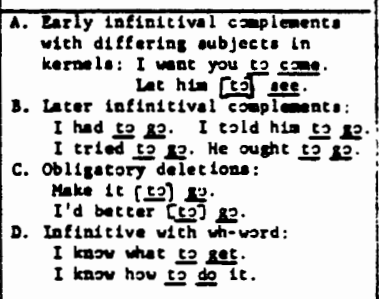 \\
\hline 6 & & 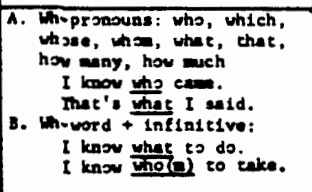 & 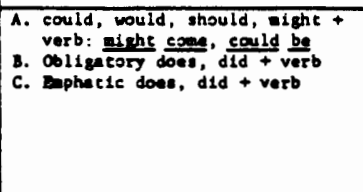 & \\
\hline 7 & 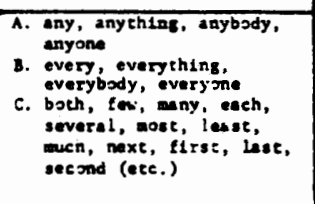 & 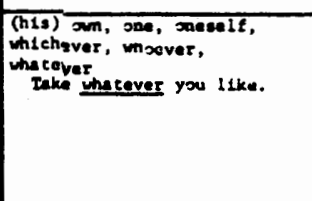 & 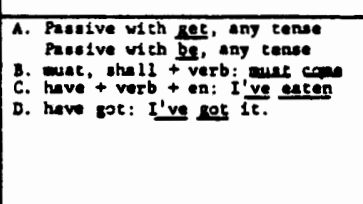 & 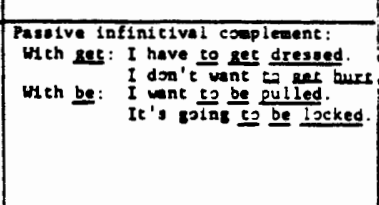 \\
\hline 8 & & & 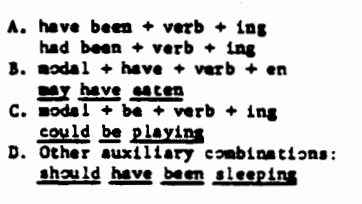 & 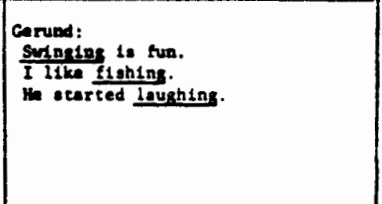 \\
\hline & & & & \\
\hline
\end{tabular}




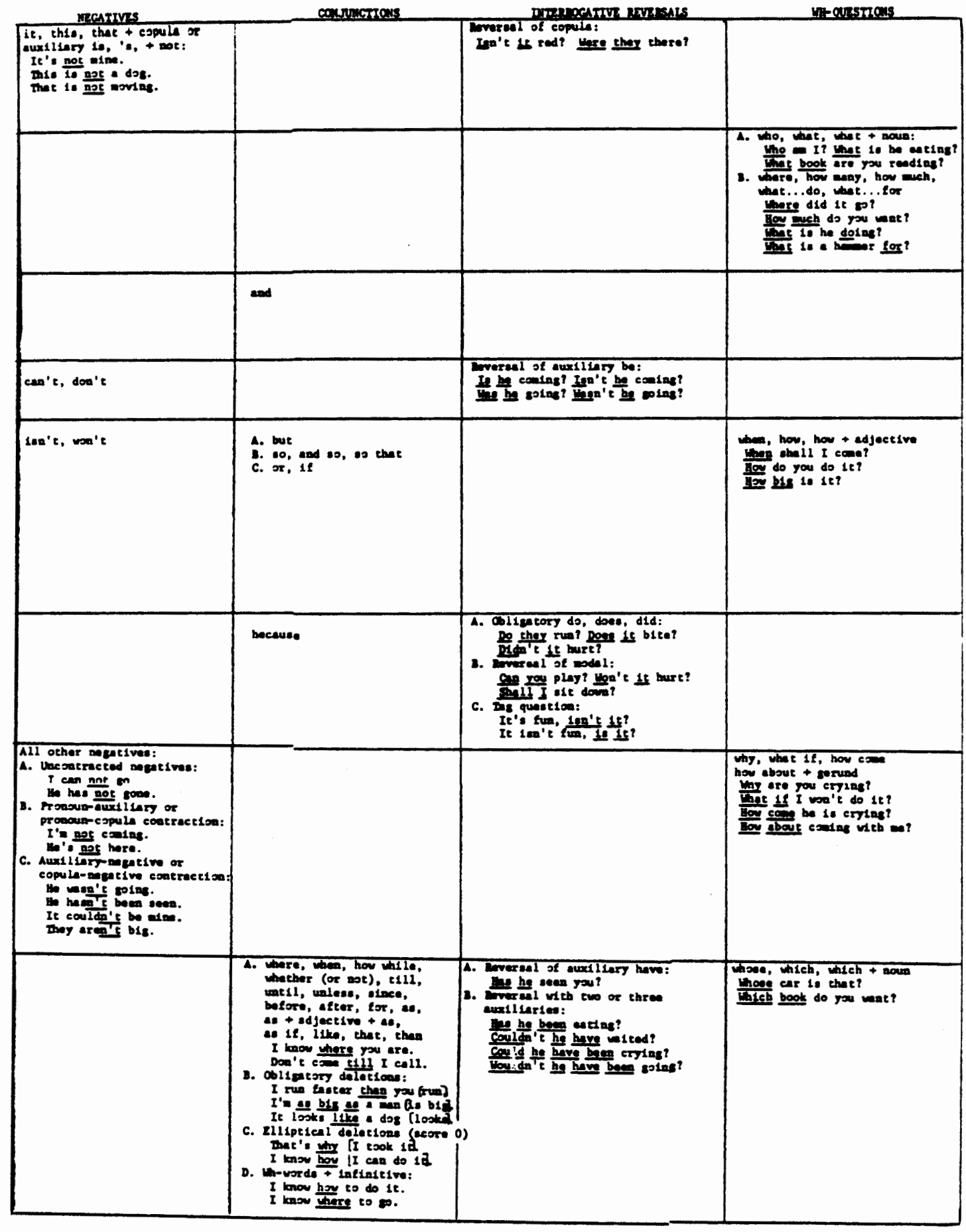




\section{APPENDIX D}

\section{SELECTING THE CORPUS FOR GRAMMATICAL ANALYSIS}

1. The corpus should contain fifty complete sentences for analysis. A sentence is judged complete if it has a noun and verb in a subject-predicate relationship. A sentence need not be correct to be included in the DSS corpus; it need have only the basic subject-verb requirement.

The following would be included as complete sentences:

Doggie no want.

Mommy bring inside.

2. The speech sample must be a block of consecutive utterances. The clinician should try to include the child's "best" performance in the sample and should scan his transcript to find the section where the block of consecutive utterances would include his "best" utterances.

3. All utterances in a language sample must be different. No repetitions of sentences are to be included.

4. Unintelligible utterances should be excluded from the corpus. If the clinician is in doubt about any part of the utterance that affects the grammatical structure, then he should discard it as unintelligible.

5. Echoed utterances should be excluded from the corpus.

(from Lee, Developmental Sentence Analysis, 1974). 


\section{APPENDIX E}

\section{TRANSCRIPTION OF TAPE}

In a speech situation between an adult and a child, tape recordings have been made. These tape recordings are the only information we have regarding the conversation taking place between these two people; so, for this reason, it is critical that the typing be accurate. There are certain general and specific instructions that you need to adhere to at all times in transcribing these tape recordings.

A. General Instructions

1. Use the letter $A$ to designate utterances by the adult and use the letter $C$ to designate utterances made by the child.

2. Any response or part of response, i.e., episode, which you cannot comprehend after diligent effort to determine what is being said, omit that entire episode from the transcript, even one word in an otherwise intelligible response. Since the language of children is not predictable by adult standards, one should not over rely on context clues for unclear or missing words. Many factors may contribute to the utterance being unintelligible: too low an intensity of utterance, environmental noise, speech defect, two people talking at once or the recorder is misfunctioning. Do note that an unintelligible episode has occurred.

3. The speech response need not be a complete thought; but, if all words are intelligible, include the response as one speech episode.

4. At times, you will find both the adult and child talking at the same time. First type the complete response of the person being interrupted and, then, type the other speaker's utterance.

5. Certain utterances are not meaningful words, but are vocal pauses, such as er, ah, andah, um, etc. Do not type vocal pauses.

6. Some words acoustically similar to meaningless interjections are considered as real words and 
should be typed, such as huh-uh, uh-huh, hm, or animal sounds which are used in lieu of the name of the animal in a thought. An example would be, "The grr is after the boy." Another example of a noise being an integral part of the response would be, "The cat goes meow."

7. Word and phrasal repetitions are excluded if they represent natural non-fluencies as opposed to repeating for stress or elaboration. An example would be, "He he he went home." The underlined words in this example would not be typed.

B. Determining and Designating a Vocal Response Unit

1. Usually, a vocal response unit is ended by a complete stop for breath.

2. At times, it is indicated by a falling inflection.

3. At other times, it is indicated by a rising inflection, such as in a question or exclamation.

4. At times, you may be able to recognize that one speech episode is complete when one person stops talking and the other person begins.

5. A vocal response unit may be the utterance of a single word, such as, uh-huh, if it is an affirmation, huh-uh for negation, huh for interrogation or oh for exclamation.

6. A single word response that is not recognizable as a word or a word approximation is considered not to be a vocal response unit and should not be transcribed. As an example, if the response to the phrase, "The flag is red, white, and..." was "dom," this would not be considered a vocal response; however, if the response was "boo," it is conceivable that this is a verbal approximation of "blue."

Remarks which appear to be clearly enumerative, separated by pauses, are considered separate response units.

(Adapted from Mathis, "Comparison of Amounts of Verbal Response Elicited from a Speech Pathologist in the Clinic and a Mother in the Home," 1970.) 


\section{APPENDIX F}

\section{DEVELOPMENTAL SENTENCE SCORING RECORD FORM}

\begin{tabular}{|c|c|c|c|c|c|c|c|c|c|c|}
\hline $\begin{array}{l}\text { NAME : } \\
\text { BIRTHDATE : }\end{array}$ & \begin{tabular}{|l|} 
Ind \\
Pro \\
\end{tabular} & & & \begin{tabular}{|l|} 
Sec \\
Verb \\
\end{tabular} & & & $\begin{array}{l}\text { Int } \\
\text { Rev } \\
\end{array}$ & & & \\
\hline SENTENCE SAMPLE & $\begin{array}{l}\text { Noun } \\
\text { Mod }\end{array}$ & $\begin{array}{l}\text { Per } \\
\text { Pro }\end{array}$ & $\begin{array}{l}\text { Main } \\
\text { Verb }\end{array}$ & & Neg & Conj & & $\begin{array}{c}\text { Wh- } \\
?\end{array}$ & $\begin{array}{l}\text { Sent } \\
\text { Point }\end{array}$ & Total \\
\hline 1. What is it? & 1 & & 1 & & & & & 2 & 1 & 5 \\
\hline 2. Is that horse trucker? & 1 & & 1 & & & & - & & 0 & 2 \\
\hline 3. This doen't stand up very good. & 1 & & 6 & & 7 & & & & 1 & 15 \\
\hline 4. I don't need that. & 1 & 1 & 4 & & 4 & & & & 1 & 11 \\
\hline $\begin{array}{l}\text { 5. (After lunchtime), he needs to } \\
\text { go to the truck. }\end{array}$ & & 2 & 2 & 5 & & & & & 1 & 10 \\
\hline 6. The farmer will try. & & & 4 & & & & & & 1 & 5 \\
\hline 7. He did try. & & 2 & 6 & & & & & & 1 & 9 \\
\hline 8. Other farmer did. & 3 & & inc & & & & & & 0 & 3 \\
\hline 9. I'm gonna play with this. & 1 & 1 & 2 & 2 & & & & & 1 & 7 \\
\hline $\begin{array}{l}\text { 10. (The) baby is sleeping on the } \\
\text { couch. }\end{array}$ & & & 1 & & & & & & 0 & 1 \\
\hline $\begin{array}{l}\text { 11. This truck takes to the } \\
\text { doctor. }\end{array}$ & 1 & & 2 & & & & & & 0 & 3 \\
\hline 12. How (do you) open the truck? & & & - & & & & & 5 & 0 & 5 \\
\hline $\begin{array}{l}\text { 13. (But) how does he drive them } \\
\text { there? }\end{array}$ & & 2,3 & 6 & & & & & 5 & 1 & 17 \\
\hline 14. Here's the doctor. & & & 1 & & & & & & 1 & 2 \\
\hline 15. Get the farmer out. & & & 1 & & & & & & 1 & 2 \\
\hline $\begin{array}{l}\text { 16. The farmer needs to be at the } \\
\text { doctor first. }\end{array}$ & 7 & & 2 & 7 & & & & & 1 & 17 \\
\hline $\begin{array}{l}\text { 17. He tried on the thing but it } \\
\text { didn't work. }\end{array}$ & 1 & 2 & 2,6 & & 7 & 5 & & & 1 & 24 \\
\hline
\end{tabular}




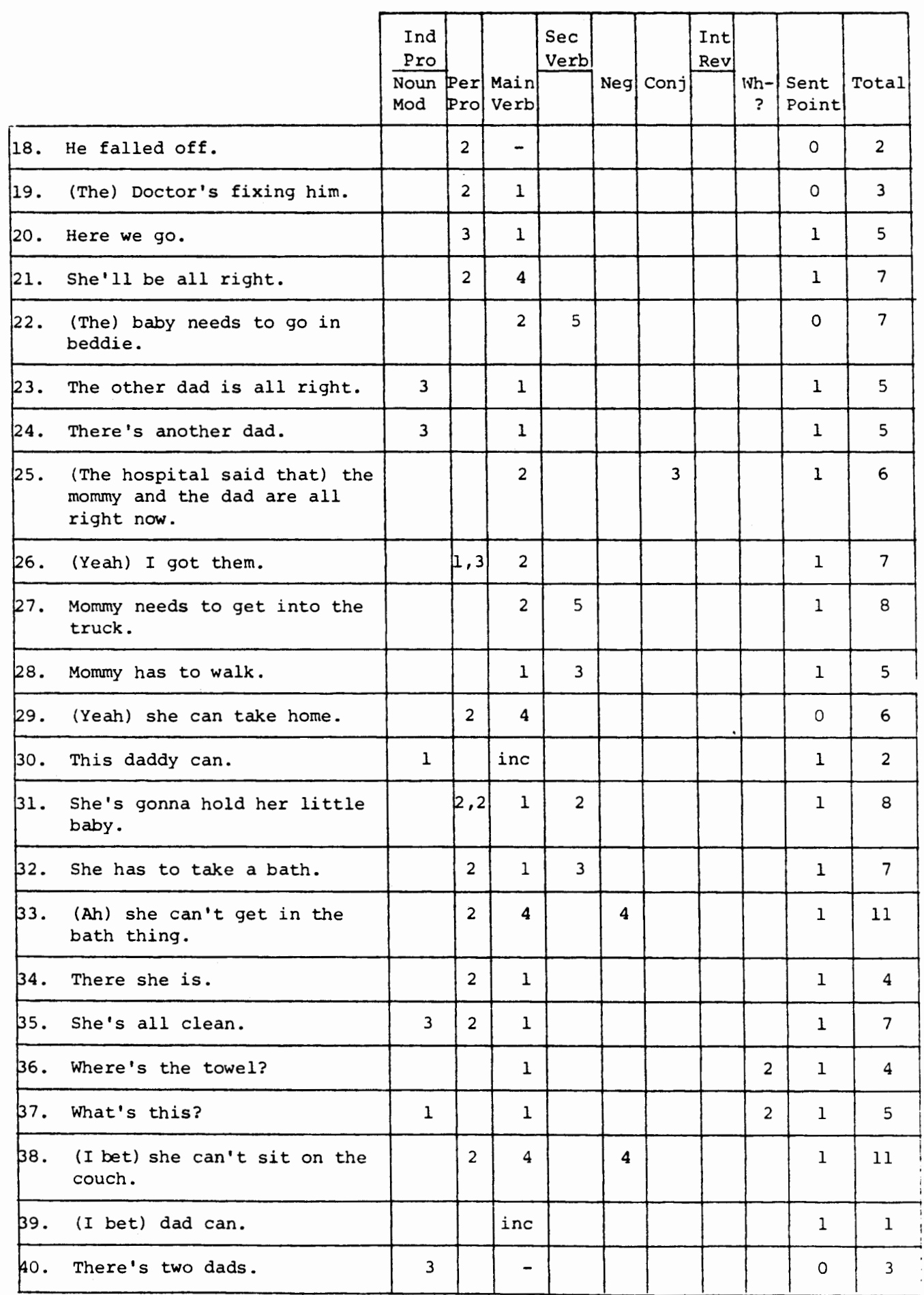




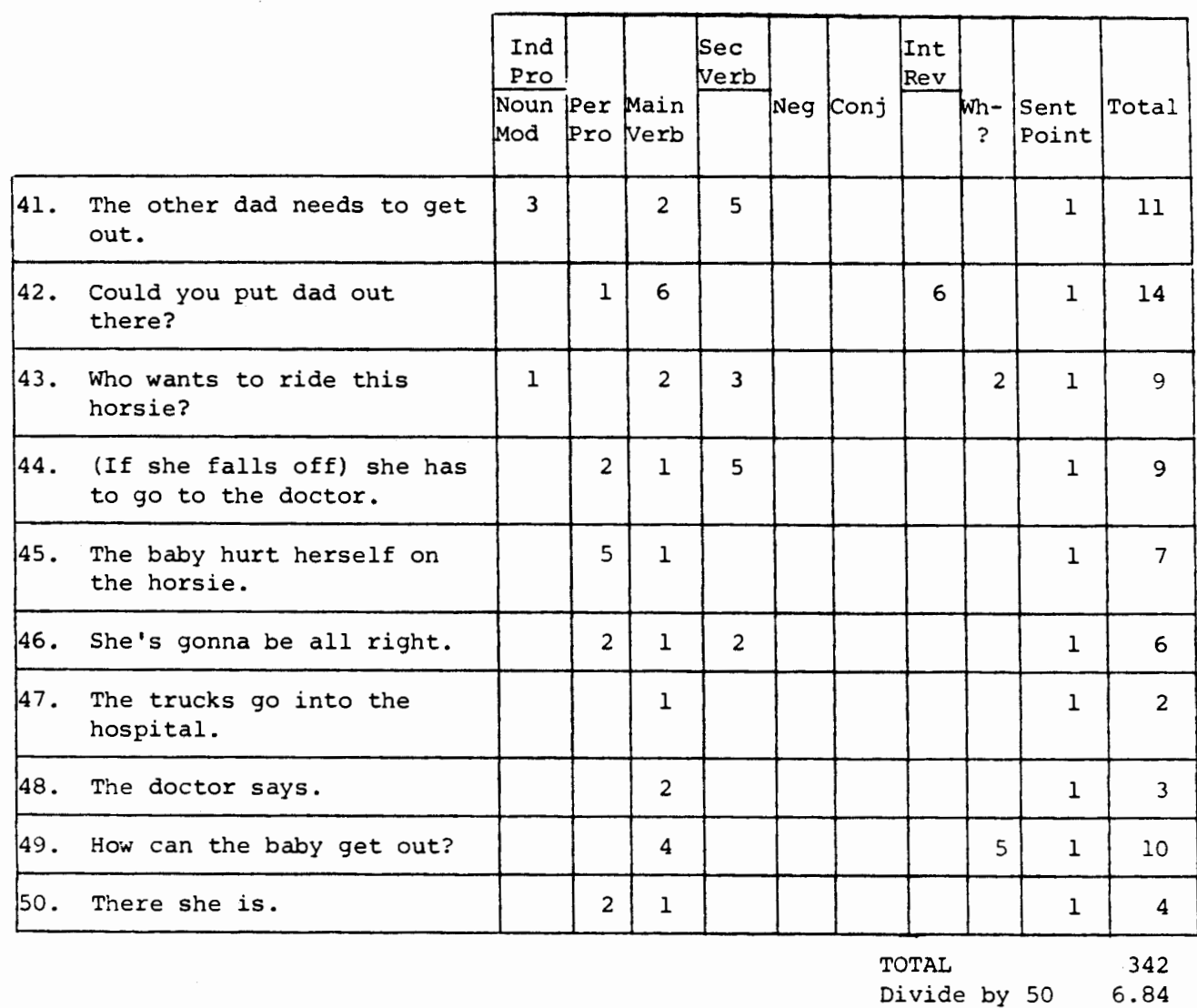




\section{APPENDIX G}

\section{THE SCORING SYSTEM}

1. If a structure is attempted but lacks some feature of standard English, then a "attempt" mark, a line, is inserted in place of the numerical score.

2. A score of 1 is added in the column labeled "sentence point" for every sentence which meets all adult standard rules. Any attempt mark within the sentence will automatically require withholding of the sentence point. The sentence point could also be withheld for any attempt on a grammatical structure not included in the eight categories under consideration (e.g. the omission of articles or prepositions). The sentence point would also be withheld for semantic irregularities.

3. Indefinite Pronouns: the same score is given whether a word is used as a pronoun or a noun modifier.

4. Personal Pronouns: grouped according to person:

Score 1 lst and 2nd person: I, me

2 3rd person: he, she

3 Plurals: we, us, they

4

5 Reflexives: myself, herself, etc.

6 Wh-pronouns: who, which

7 (his) own, one, oneself: One hopes for peace.

5. Main Verbs:

Score 1 a. uninflected verb: I see you.

b. copula, is or 's: It's red.

c. is +verb+ing: He is coming.

2 a. -s and -ed: plays, played

b. irregular past: ate, saw

c. copula: am, are, was, were

3

4 a. can, will, may+verb: may go

b. obligatory do+verb: don't go

c. emphatic dotverb: I do see.

5

6 a. could, would, should, might+verb: might come

b. obligatory does, did+verb

c. emphatic does, did+verb

7 a. passive with get, any tense passive with be, any tense

b. must, shall+verb+en: I've eaten 
c. havetverbten: I've eaten

d. have got: I've got it.

Occasional deletions in verb forms are part of adult standard English and should not be regarded as immaturities in children's language. For example, if the clinician asks, "Does your mother work?" the child may answer, "No, she doesn't." Such elliptical verb forms are not given a score on the DSS; the abbreviation for "incomplete," "inc" is inserted on the record sheet in place of either a score or an attempt mark. Since adult grammatical rules contain elliptical verb forms, the sentence point is allowed.

6. Secondary Verbs

Score 1

2 Five early developing infinitives:

I wanna see (want to see)

I'm gonna see (going to see)

I gotta see (got to see)

Lemme (to) see (let me (to) see)

Let's (to) play (let us (to) play)

3 Noncomplimenting infinitives

I stopped to play.

I'm afraid to look.

I's hard to do that.

4 Participle, present or past:

I see a boy running.

I found the toy broken.

5 a. Early infinitives with differing subjects in basic sentences:

I want you to come.

Let him (to) see.

b. Later infinitval complements:

I had to go. I told him to go.

I tried to go. He ought to go.

c. Obligatory deletions: Make it (to) go. I'd better (to) go.

d. Infinitive with wh-word:

I know what to get.

I know how to do it.

6

7 Passive infinitive:

with get: I have to get dressed.

I don't want to get hurt.

with be: I want to be pulled.

8 Gerund : It's going to be locked.

Swinging is fun.

I like fishing.

He started laughing. 
7. Negative

Score 1 it, this, that+copula or auxilliary is, 's, + not:

It's not mine.

This is not a dog.

That is not moving.

2

3

4 can't, don't

5 isn't, won't

6

7 All other negatives:

a. Uncontracted negatives:

I can not go.

He has not gone.

b. Pronoun-auxilliary or pronoun-copula contraction:

I'm not coming.

He's not here.

c. Auxilliary-negative or copula-negative contraction:

He wasn't going.

He hasn't been seen.

It couldn't be mine.

They aren't big.

8. Conjunction

Score 1

2

3 and

4

5 a. but

b. so, and so, so that

c. or, if

6 because

7

8 a. where, when, how, while, whether (or not), till, until, unless, since, before, after, for, as, astadjectivet as, as if, like, that, than

I know where you are.

Don't come till I call.

b. Obligatory deletions:

I run faster than you (run).

I'm as big as a man (is big).

It looks like a dog (looks).

c. Elliptical deletions (score 0)

That's why (I took it).

I know how (I can do it).

d. Wh-words + infinitive

I know how to do it.

I know where to go. 
9. Interrogative Reversal

Score 1 Reversal of copula:

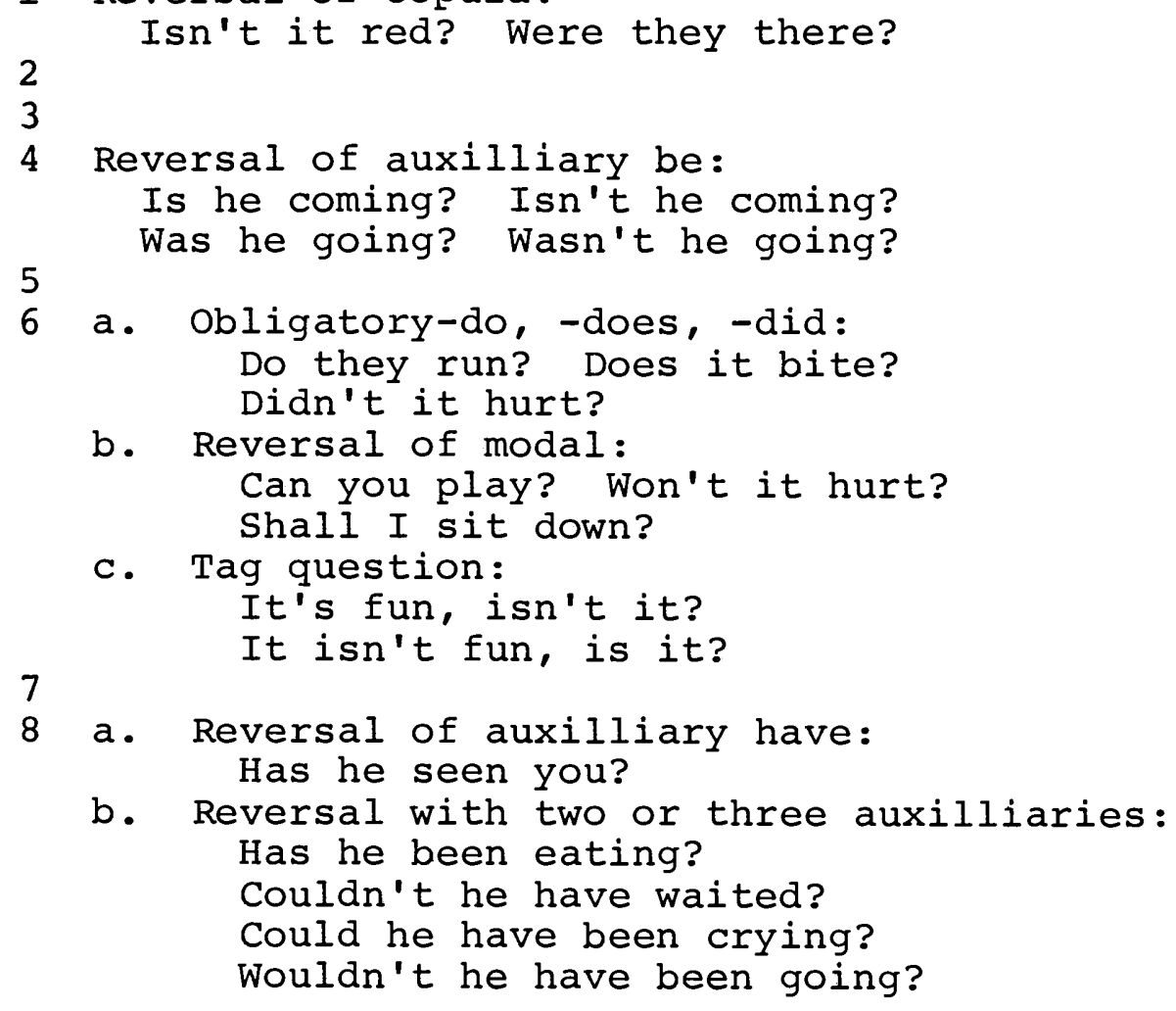

8 a. Reversal of auxilliary have:

Has he seen you?

b. Reversal with two or three auxilliaries:

Has he been eating?

Couldn't he have waited?

Could he have been crying?

Wouldn't he have been going?

10. Wh-questions

Score 1

2 a. who, what, what+noun

Who am I? What is he eating?

What book are you reading?

b. where, how many, how much, what...do, what.... for

Where did it go?

How much do you want?

What is he doing?

What is a hammer for?

3

4

5 when, how, how tadjective When shall I come?

How do you do it?

How big is it?

6

7 why, what if, how, come, how about+gerund Why are you crying?

What if I won't do it?

How come he is crying?

How about coming with me? 
8 whose, which, which+noun

Whose car is that?

Which book do you want?

Deriving the Developmental Sentence Score:

When all fifty sentences in the language sample have been individually scored, the mean sentence score is derived by adding the total sentence scores and dividing by fifty. This is known as the child's DSS.

(from Lee, Developmental Sentence Analysis, 1974) 